\title{
Optimal Taxation with Risky Human Capital and Retirement Savings*
}

\author{
Radoslaw Paluszynski ${ }^{\dagger} \quad$ Pei Cheng $\mathrm{Yu}^{\ddagger}$
}

This version:

May 21, 2019

\begin{abstract}
We study optimal tax policies with human capital investment and retirement savings for present-biased agents. Agents are heterogeneous in their innate ability and make risky education investments which determines their labor productivity and affects their consumption path. We characterize the optimal wedges and show that they are different across education groups. More specifically, we demonstrate how the optimal policy encourages human capital investment with savings incentives. We show that the optimum can be implemented with income-contingent student loans, and existing retirement policies augmented by a new tax instrument that subsidizes retirement savings for college graduates. The proposed instrument takes the form of employer's 401(k) matching contribution proportional to the repayment of student loans, and mimics the latest policy proposals that aim to incentivize college education. We show that the optimal tax system yields significant welfare gains relative to the optimal policies designed for time-consistent agents.
\end{abstract}

Keywords: Present bias, Human capital, Retirement, Sequential screening

\footnotetext{
*The authors would like to thank German Cubas, David Rahman, Satoshi Tanaka and Hsin-Jung Yu.

†University of Houston (e-mail: rpaluszynski@uh.edu)

${ }^{\ddagger}$ University of New South Wales (e-mail: pei-cheng.yu@unsw.edu.au)
} 


\section{Introduction}

This paper investigates how to design retirement savings policies to incentivize investment in human capital. Over the past two decades, the average cost of college has approximately doubled at both four-year public schools and four-year private institutions (College Board, 2018). This has led to the average student debt of freshly minted college graduates to double from 2003 to 2013 (Lochner and Monge-Naranjo, 2015). Even though the returns to education remain high, the ever increasing costs could discourage education investment due to the lack of insurance against risky education outcomes. Furthermore, college graduates with student loans save less for retirement, so the high costs of college could enhance the issue of insufficient retirement savings (Munnell et al., 2016; Rutledge et al., 2018).

Despite the importance of human capital investment and retirement savings, the literature has not explored the design of education and retirement policies jointly. Yet, these topics have been on the frontier of policy debates in the last few years. In 2012, then-President Obama introduced the Pay As You Earn Repayment Plan, an income-contingent student loan. More recently, the IRS ruling number 201833012 consented that employers can contribute to the retirement accounts of employees paying off their student debt, even if they do not make any 401(k) contributions. Following this development, the US Congress introduced the Retirement Parity for Student Loans Act in late 2018, which would officially qualify student loan repayments for employer matching contributions.

To formulate the optimal education, income taxation and retirement policies, this article studies dynamic Mirrlees taxation with present-biased agents in a life-cycle model. We focus on present-biased agents, because recent empirical evidence show that self-control problems affect both education attainment (Cadena and Keys, 2015) and retirement savings (Angeletos et al., 2001; Laibson et al., 2017). As a result, the government attempts to offset the present bias that is it acts paternalistically. In our framework, agents first choose their level of education and then work before they retire. Agents initially differ in their innate ability, and productivity is drawn from a distribution determined by their innate ability and level of education. Both the innate ability and productivity are the private information of the agents, so the government sequentially screens the agents and designs policies conditioned on the observed education investment and income.

We characterize the optimal intertemporal distortions for present-biased agents in our sequential screening environment. We show that the usual inverse Euler equation does not hold. When agents invest in higher education, the inverse marginal utility of consumption is strictly higher than next period's expected inverse marginal utility. This implies that consumption is more front-loaded for high-educated agents compared to the time-consistent 
case. On the other hand, for low-educated agents, the inverse marginal utility of consumption is strictly lower than next period's expected inverse marginal utility. This implies that consumption for low-educated agents is more back-loaded relative to the time-consistent case. As a result, the optimal student loans are more generous to gratify the presentbiased agents and encourage the ones with high innate ability to invest in education. When agents are saving for retirement, the intertemporal distortion for high-educated agents is less severe than what it would have been if they saved on their own. On the other hand, for agents with low education, the distortion to retirement savings is monotonically increasing in their income. This is because present-biased agents are tempted to over-consume in the present, but they demand commitment for the future. The optimal policy incentivizes human capital investment by providing high-educated agents with a savings vehicle that offsets the bias, while the income-contingent distortion in retirement savings of the low-educated agents relaxes the informational constraints.

We also derive the optimal labor wedge for our environment when agents have entered the workforce. The theoretical characterization differs from those obtained with time-consistent agents. More precisely, two new opposing forces are introduced when agents are present biased. First, present-biased agents are less sensitive to future incentives. As a result, the labor distortion decreases to mitigate the present-biased agents' tendency to undervalue future incentives. Second, by helping agents commit to saving for retirement, the government is distorting intertemporal decisions from the present-biased agents' perspective. Therefore, the introduction of commitment increases labor distortions. In the quantitative exercise, we show that the two economic forces approximately offset each other, so the optimal labor wedge with present-biased agents is very close to the one for time-consistent agents.

Our theoretical insights provide a novel perspective on the design of retirement policies as a function of education. We consider two ways of decentralizing the constrained efficient allocations. For one of the implementations, we introduce retirement accounts with income and education contingent savings subsidies. We also consider an implementation where non-college-educated individuals rely mainly on social security benefits during retirement, while college-educated individuals are supplemented with a fraction of their student loan repayments in their retirement savings accounts. This latter implementation is attractive because it uses existing policy instruments, and it relates to the recent IRS ruling and the Retirement Parity for Student Loans Act, which allows employers to deposit a fraction of the student loans repayment into their employees' retirement account. For both implementation schemes, the government provides individuals with income-contingent student loans.

Finally, we bring our model to the data by inferring realistic distributions of skills among high school and college graduates, calibrating the structural parameters and approximating 
the current tax system. We show that the theoretical predictions are quantitatively significant. Optimal tax schedules involve extensive use of the savings wedge during working life which, crucially, differs across income and education groups. High-ability college graduates can expect more help from the government in smoothing out their higher income over the life cycle, which ex-ante provides them with incentive to choose college education. We show that the welfare gains from our optimal tax are potentially significant, exceeding $1 \%$ of lifetime consumption relative to the world with optimal policies dedicated to time-consistent agents.

\section{$1.1 \quad$ Related Literature}

This paper contributes to the literature on optimal human capital policies. Bovenberg and Jacobs (2005) studies optimal education and income policies in an environment where schooling increases productivity. However, human capital investment in their environment is riskless, which is different from empirical studies that find returns to human capital investments to be risky (Cunha and Heckman, 2007). This paper captures the risky returns to education by modeling productivity as a random draw from a distribution determined by human capital. There are other papers that have studied how risk from human capital investments affects the design of optimal policy. Anderberg (2009) finds that how human capital affects the degree of wage risk matters for optimal policy. Grochulski and Piskorski (2010) focuses on the optimal capital taxation in an environment where initial human capital investment decision affects future productivity, but agents share the same innate ability and human capital investment is unobservable. Craig (2019) studies a setting where employers observe informative but imperfect signals to infer the human capital investment of ex-ante

heterogeneous workers. Our paper focuses on how initial differences in innate ability affects the design of policies when investment in education is observable.

Several papers have also examined the optimal policy for human capital acquisition over the working age. Bohacek and Kapicka (2008) and Kapicka (2015) study the optimal tax policy when human capital investment is deterministic while the agent works. Stantcheva (2017) studies an environment where agents make monetary investments in each period to build up their stock of human capital, and productivity is determined by the human capital stock and stochastic ability. Makris and Pavan (2018) examine the learning-by-doing aspect of human capital accumulation, so human capital is acquired stochastically as a by-product from labor effort and not from external investments. Kapicka and Neira (2015) considers risky but unobservable human capital investment, so tax policies are not conditional upon this investment. In contrast to these papers, our work focuses on human capital acquired before agents enter the labor force. 
Gary-Bobo and Trannoy (2015) and Findeisen and Sachs (2016) consider environments most similar to ours. They examine optimal education and income tax policies in a setting where agents differ in initial ability and make risky investments in education before they enter the labor market. Our paper models initial ability and the risk from human capital investment in a similar fashion to their paper. However, we consider present-biased agents. In our setting, we show it is important to design education, tax and retirement policies simultaneously. For time-consistent agents, as in their papers, introducing distortions in retirement savings does not increase investments in human capital or labor supply. With present-biased agents, we find that optimal retirement policies are contingent on education.

Our paper contributes to the literature on optimal policies when agents have behavioral biases. Farhi and Gabaix (2017) use sparse maximization (Gabaix, 2014) to study optimal taxation of behavioral agents in a static setting. Lockwood (2016) studies optimal income taxation with present-biased agents where wages depend on past work effort. He shows how present bias has a potentially large effect on the optimal marginal income tax rate. We find an economic force similar to the one in Lockwood (2016), but we also discover a novel opposing force that quantitatively negates the effect of present bias on the optimal labor wedge when the government tries to smooth consumption. There are also papers that focus on the design of retirement savings policies for time-inconsistent agents in a Mirrlees setting. Moser and de Souza e Silva (2017) consider a multi-dimensional screening environment, where agents are heterogeneous in time inconsistency and productivity. Yu (2018a) examines a multidimensional screening environment with off-path policies, where the agents' degree of bias, productivity and level of sophistication are hidden. To the best of our knowledge, this is the first paper to analyze optimal policies with risky human capital for time-inconsistent agents.

\section{$2 \quad$ Model}

We consider a life-cycle model with three periods: $t=0,1,2$. Agents differ in their innate ability or their effectiveness in human capital accumulation $\gamma \in\{H, L\}$ with $H>L$. Intuitively, $H$-agents are innately more skilled than $L$-agents. The share of $\gamma$-agents is $\pi_{\gamma} \in(0,1)$ with $\pi_{H}+\pi_{L}=1$. At $t=0$, they choose their education investment $e \in\left\{e_{L}, e_{H}\right\}$, with $e_{H} \geq e_{L}$. The level of education investment $e$ is exogenous, which is meant to capture the binary decision of whether to invest in higher-education (invest $e_{H}$ ) or not (invest $e_{L}$ ). Human capital depends on both $\gamma$ and $e$, which we denote as $\kappa(e, \gamma)$. We assume $\kappa$ is strictly increasing in both arguments, so education helps raise human capital. The government observes $e$ while $\kappa$ and $\gamma$ are the agents' private information. We refer to $\gamma$ as the ex-ante private information. 
At $t=1$, agents enter the labor market, and privately learn their productivity $\theta \in \Theta=$ $[\underline{\theta}, \bar{\theta}] \subset \mathbb{R}_{+}$. Productivity is drawn from a differentiable distribution with c.d.f. $F(\theta \mid \kappa)$, which depends on human capital $\kappa$ and are ranked according to first order stochastic dominance: if $\kappa>\kappa^{\prime}, F(\theta \mid \kappa)<F\left(\theta \mid \kappa^{\prime}\right), \forall \theta \in \Theta$. This means that human capital investment is risky but agents with higher human capital are more likely to be productive. Let $f(\theta \mid \kappa)$ denote the p.d.f., and assume $f(\theta \mid \kappa)$ is bounded away from zero for any $\theta$ and $\kappa$. An agent with productivity $\theta$ and provides work effort $l$ would produce output $y=\theta l$. We refer to $\theta$ as the ex-post private information. The government observes output $y$, but not productivity $\theta$ and labor supply $l$. Finally, at $t=2$, agents retire and consume their savings.

Agents of innate ability $\gamma$ have the following utility at $t=0$

$$
U_{0}\left(\left\{c_{t}\right\}, e, y ; \gamma\right)=\delta_{0}(e) u\left(c_{0}\right)+\beta \delta_{1}(e) \int_{\Theta}\left[u\left(c_{1}\right)-h\left(\frac{y}{\theta}\right)+\delta_{2} u\left(c_{2}\right)\right] f(\theta \mid \kappa) d \theta
$$

The flow utilities are defined for for $c_{t}, y \geq 0$, and we assume that $u^{\prime}(\cdot),-u^{\prime \prime}(\cdot), h^{\prime}(\cdot), h^{\prime \prime}(\cdot)>$ 0 with $h(0)=0$ The agents are present-biased with short-run discount factor $\beta<1$ and

long-run discount factors $\delta_{t}$. Furthermore, $\delta_{0}$ and $\delta_{1}$ are functions of $e$ to reflect how schooling affects the length of $t=0$, while $\delta_{2}$ is assumed to be constant across education groups because the length of a working period is assumed to be the same for all agents. Agents of type $(\gamma, \theta)$ have the following utility at $t=1$

$$
U_{1}\left(c_{1}, c_{2}, y ; \gamma, \theta, e\right)=u\left(c_{1}\right)-h\left(\frac{y}{\theta}\right)+\beta \delta_{2} u\left(c_{2}\right)
$$

so the agents are quasi-hyperbolic (Laibson, 1997).

\subsection{Planning Problem}

The government is paternalistic and treats present bias as an error and attempts to correct it. The basis for this is because $\beta \neq 1$ reflects a self-control problem that agents disapprove of in every other period. Therefore, the policies attempt to increase investment in education and raise retirement savings. As is standard, we first characterize the allocations that maximize social welfare subject to the informational constraints. Then in later sections, we discuss the decentralized policies that implement the efficient allocations in equilibrium.

We use the direct mechanism, where agents report their private information to the government, to characterize the constrained efficient allocation. The government designs

$$
P=\left\{c_{0}(\gamma),\left[c_{t}(\gamma, \theta), y(\gamma, \theta)\right]_{t>0, \theta \in \Theta}\right\}_{\gamma}
$$


Since agents privately learn their innate ability $\gamma$ and productivity $\theta$ sequentially, by the dynamic version of the revelation principle, we require $P$ to be incentive compatible for each period. Let $U_{1}\left(\theta^{\prime} ; \gamma, \theta\right)$ denote the utility of a type $(\gamma, \theta)$ agent who reported $\gamma$ truthfully and reports $\theta^{\prime} \in \Theta$ in $t=1$. The ex-post incentive compatibility constraints are $\forall \theta, \theta^{\prime} \in \Theta$,

$$
U_{1}(\gamma, \theta)=U_{1}(\theta ; \gamma, \theta) \geq U_{1}\left(\theta^{\prime} ; \gamma, \theta\right)
$$

The ex-post incentive compatibility constraints ensure the agents report $\theta$ truthfully. Let

$$
U_{0}\left(\gamma^{\prime} ; \gamma\right)=\delta_{0}\left(e_{\gamma^{\prime}}\right) u\left(c_{0}\left(\gamma^{\prime}\right)\right)+\beta \delta_{1}\left(e_{\gamma^{\prime}}\right) \int_{\Theta}\left[U_{1}\left(\gamma^{\prime}, \theta\right)+(1-\beta) \delta_{2} u\left(c_{2}\left(\gamma^{\prime}, \theta\right)\right)\right] d F\left(\theta \mid \kappa_{\gamma^{\prime}, \gamma}\right)
$$

where $\kappa_{\gamma^{\prime}, \gamma}=\kappa\left(e_{\gamma^{\prime}}, \gamma\right)$ and let $\kappa_{\gamma, \gamma}=\kappa_{\gamma}$. Then, the ex-ante incentive compatibility constraints are for any $\gamma, \gamma^{\prime}$ are

$$
U_{0}(\gamma)=U_{0}(\gamma ; \gamma) \geq U_{0}\left(\gamma^{\prime} ; \gamma\right)
$$

The ex-ante incentive constraints ensure that the agents report $\gamma$ truthfully at $t=0$.

Let $R_{t}$ denote the gross rate of return and assume $\delta_{t} R_{t}=1$. The constrained efficient planning problem maximizes the utilitarian welfare criterion

$$
\sum_{\gamma} \pi_{\gamma}\left\{\delta_{0}\left(e_{\gamma}\right) u\left(c_{0}(\gamma)\right)+\delta_{1}\left(e_{\gamma}\right) \int_{\Theta}\left[u\left(c_{1}(\gamma, \theta)\right)-h\left(\frac{y(\gamma, \theta)}{\theta}\right)+\delta_{2} u\left(c_{2}(\gamma, \theta)\right)\right] f\left(\theta \mid \kappa_{\gamma}\right) d \theta\right\}
$$

subject to the resource constraint

$$
\sum_{\gamma} \pi_{\gamma}\left\{-e_{\gamma}-\frac{c_{0}(\gamma)}{R_{0}\left(e_{\gamma}\right)}+\frac{1}{R_{1}\left(e_{\gamma}\right)} \int_{\Theta}\left[y(\gamma, \theta)-c_{1}(\gamma, \theta)-\frac{1}{R_{2}} c_{2}(\gamma, \theta)\right] f\left(\theta \mid \kappa_{\gamma}\right) d \theta\right\} \geq 0
$$

and the ex-post and ex-ante incentive compatibility constraints.

It is worth emphasizing that education is costly for two reasons. First, it is costly in terms of resources. Second, it is costly in terms of time, because receiving education delays entry into the labor market. Due to these reasons, present-biased agents are less willing to invest in human capital.

\subsection{Characterizing Incentive Compatibility}

Here, we derive two lemmas that simplify the ex-ante and ex-post incentive compatibility conditions. The following lemma characterizes the ex-post incentive compatibility constraint. 
Lemma 1 For any $\gamma, P$ is ex-post incentive compatible if and only if (i.) $y(\gamma, \theta)$ is non-decreasing in $\theta$, and (ii.) $U_{1}(\gamma, \theta)$ is absolutely continuous in $\theta$, with $\frac{\partial U_{1}(\gamma, \theta)}{\partial \theta}=$ $\frac{y(\gamma, \theta)}{\theta^{2}} h^{\prime}\left(\frac{y(\gamma, \theta)}{\theta}\right)$.

Lemma 1 characterizes the set of policies that are ex-post incentive compatible. Its proof is standard so it is omitted. It also provides us with the usual revenue equivalence:

$$
U_{1}(\gamma, \theta)=U_{1}(\gamma, \underline{\theta})+\int_{\underline{\theta}}^{\theta} \frac{y(\gamma, x)}{x^{2}} h^{\prime}\left(\frac{y(\gamma, x)}{x}\right) d x
$$

There are two main difficulties in characterizing the ex-ante incentive compatibility for time-inconsistent agents. First, local ex-ante incentive compatibility does not necessarily imply global ex-ante incentive compatibility when agents are time-inconsistent (Halac and Yared, 2014; Galperti, 2015; Yu, 2018b). This paper simplifies the problem by examining the case with two levels of innate ability.

The second difficulty lies in the direction of the relevant deviation. Usually, the relevant deviation is downwards when agents are time consistent. Findeisen and Sachs (2016) showed that part of the sufficient condition for this to be true requires output $y(\gamma, \theta)$ to be weakly increasing with innate ability $\gamma$. However, Yu (2018b) showed that the optimal allocations are usually non-monotonic with respect to ex-ante information, because the non-monotonicity helps relax the ex-ante informational constraints when agents are time-inconsistent. Therefore, it is unclear which ex-ante incentive compatibility constraint is relevant for our analysis. We provide a sufficient condition such that the usual downward ex-ante incentive constraint binds and the upward ex-ante incentive constraint is automatically satisfied.

Lemma 2 Suppose $P$ satisfies ex-post incentive compatibility, then if the returns to education for high innate ability is sufficiently larger than low innate ability, in essence,

$$
\left|F\left(\theta \mid \kappa_{H}\right)-F\left(\theta \mid \kappa_{H, L}\right)\right|-\left|F\left(\theta \mid \kappa_{L, H}\right)-F\left(\theta \mid \kappa_{L}\right)\right|
$$

is sufficiently large and positive, then at the optimum, $U_{0}(L) \geq U_{0}(H ; L)$ and $U_{0}(H)=$ $U_{0}(L ; H)$.

Lemma 2 states that if there is significant increasing differences in ability and education, then the relevant deviation is for $H$-agents to mimic $L$-agents. For the theoretical analysis, we focus on the case when Lemma 2 applies. This is because there is empirical evidence that the returns to education are significantly higher for high innate ability agents (Carneiro and Heckman, 2003). In our quantitative exercise, we estimate the productivity distributions and find that $f\left(\theta \mid \kappa_{L, H}\right)$ and $f\left(\theta \mid \kappa_{L}\right)$ are almost indistinguishable while $\left|F\left(\theta \mid \kappa_{H}\right)-F\left(\theta \mid \kappa_{H, L}\right)\right|$ 
is large and positive (Figure 1), so the ex-ante incentive constraint for $H$-agents binds while it is automatically satisfied for $L$-agents at the optimum.

\section{$2.3 \quad$ Wedges}

To understand how present-bias and informational frictions affect the optimal tax policy, the paper will focus on characterizing the optimal intertemporal and labor wedges.

The intertemporal wedge in $t=0$ for innate ability $\gamma$ is

$$
\tau_{0}^{k}(\gamma)=1-\frac{u^{\prime}\left(c_{0}(\gamma)\right)}{\mathbb{E}_{\theta}\left[u^{\prime}\left(c_{1}(\gamma, \theta)\right)\right]}
$$

and the intertemporal wedge in $t=1$ for type $(\gamma, \theta)$ is

$$
\tau_{1}^{k}(\gamma, \theta)=1-\frac{u^{\prime}\left(c_{1}(\gamma, \theta)\right)}{u^{\prime}\left(c_{2}(\gamma, \theta)\right)}
$$

When $\tau^{k} \neq 0$, then consumption is not smoothed across time. More specifically, if $\tau_{t}^{k}>0$, then agents are saving less than the efficient amount in $t$. Similarly, if $\tau_{t}^{k}<0$, then agents are over-saving compared to the efficient amount in $t$.

The labor wedge in $t=1$ for type $(\gamma, \theta)$ is

$$
\tau^{w}(\gamma, \theta)=1-\frac{h^{\prime}\left(\frac{y(\gamma, \theta)}{\theta}\right)}{\theta u^{\prime}\left(c_{1}(\gamma, \theta)\right)} .
$$

Since agents' equilibrium wage is equal to their productivity $\theta$ in a competitive labor market, if $\tau^{w} \neq 0$, then agents are not working at the efficient level. In particular, if $\tau^{w}>0$, then there is an under-supply of labor. While if $\tau^{w}<0$, then agents are working too much compared to the efficient level.

\section{Theoretical Results}

In this section, we derive the optimal intertemporal and labor distortions, which are crucial for determining the optimal tax policies.

\subsection{Intertemporal Wedges}

The following proposition provides the inverse Euler equations for present-biased agents, which are necessary conditions for optimality. 
Proposition 1 The constrained efficient allocation satisfies the inverse Euler equations:

$$
\begin{aligned}
\mathbb{E}_{\gamma}\left(\frac{1}{u^{\prime}\left(c_{0}(\gamma)\right)}\right) & =\mathbb{E}_{\gamma}\left[\mathbb{E}_{\theta}\left(\frac{1}{u^{\prime}\left(c_{1}(\gamma, \theta)\right)} \mid \gamma\right)\right], \\
\mathbb{E}_{\theta}\left(\frac{1}{u^{\prime}\left(c_{1}(\gamma, \theta)\right)}\right) & =\mathbb{E}_{\theta}\left(\frac{1}{u^{\prime}\left(c_{2}(\gamma, \theta)\right)}\right) \text { for any } \gamma .
\end{aligned}
$$

In particular, for any $\theta \in \Theta$,

$$
\begin{gathered}
\frac{1}{\beta u^{\prime}\left(c_{2}(H, \theta)\right)}=\frac{1}{u^{\prime}\left(c_{1}(H, \theta)\right)}+\left(\frac{1-\beta}{\beta}\right)\left(\frac{\pi_{H}+\beta \mu}{\pi_{H}+\mu}\right) \frac{1}{u^{\prime}\left(c_{0}(H)\right)} \\
\frac{1}{\beta u^{\prime}\left(c_{2}(L, \theta)\right)}=\frac{1}{u^{\prime}\left(c_{1}(L, \theta)\right)}+\left(\frac{1-\beta}{\beta}\right)\left(\frac{\pi_{L}-\beta \mu\left(\frac{f\left(\theta \mid \kappa_{L, H}\right)}{f\left(\theta \mid \kappa_{L}\right)}\right)}{\pi_{L}-\mu}\right) \frac{1}{u^{\prime}\left(c_{0}(L)\right)},
\end{gathered}
$$

where $\mu=\left[u^{\prime}\left(c_{0}(L)\right)-u^{\prime}\left(c_{0}(H)\right)\right]\left[\frac{u^{\prime}\left(c_{0}(L)\right)}{\pi_{L}}+\frac{u^{\prime}\left(c_{0}(H)\right)}{\pi_{H}}\right]^{-1}$.

Proposition 1 follows from considering variations around any incentive compatible allocation that do not affect incentive compatibility and welfare. The optimal allocation minimizes the resources expended, which satisfies (1) and (2).

To understand Proposition 1, first consider the standard inverse Euler equation at $t=0$ for time-consistent agents:

$$
\frac{1}{u^{\prime}\left(c_{0}(\gamma)\right)}=\mathbb{E}_{\theta}\left(\frac{1}{u^{\prime}\left(c_{1}(\gamma, \theta)\right)}\right) \text { for any } \gamma
$$

By Jensen's inequality, the inverse Euler equation for time-consistent agents implies $u^{\prime}\left(c_{0}(\gamma)\right)<\mathbb{E}_{\theta}\left[u^{\prime}\left(c_{1}(\gamma, \theta)\right)\right]$ for any $\gamma$. Due to informational constraints, the transfer of consumption from $t=0$ to $t=1$ for time-consistent agents is restricted regardless of their ex-ante private information. ${ }^{1}$ Therefore, the intertemporal wedge $\tau_{0}^{k}$ is strictly positive for any innate ability $\gamma$.

With present-biased agents, the government can relax the ex-ante incentive compatibility constraint by increasing the intertemporal wedge for $H$-agents while decreasing the wedge for $L$-agents at $t=0$. To see this, if we take expectation of (3) and (4) with respect to $\theta$, then by (2) we have

$$
\frac{1}{u^{\prime}\left(c_{0}(H)\right)}>\mathbb{E}_{\theta}\left(\frac{1}{u^{\prime}\left(c_{1}(H, \theta)\right)}\right)
$$

\footnotetext{
${ }^{1}$ See Golosov et al. (2003) for more on the inverse Euler equation for time-consistent agents.
} 
and

$$
\frac{1}{u^{\prime}\left(c_{0}(L)\right)}<\mathbb{E}_{\theta}\left(\frac{1}{u^{\prime}\left(c_{1}(L, \theta)\right)}\right) .
$$

Comparing it with the standard inverse Euler equation, the consumption for high-educated agents is even more front-loaded while the consumption is relatively back-loaded for loweducated agents. ${ }^{2}$ In other words, the government exacerbates the intertemporal distortion for $H$-agents to satisfy their temptation, which encourages them to accumulate human capital. Furthermore, the smaller intertemporal distortion for $L$-agents helps deter downward deviations and relaxes the ex-ante informational constraint. As a result, the best the government can do is to choose consumption such that the inverse marginal utility is equalized in expectation, as shown in (1).

Next, note that the optimal intertemporal decision at $t=1$ for time-consistent agents satisfies the standard Euler equation:

$$
u^{\prime}\left(c_{1}(\gamma, \theta)\right)=u^{\prime}\left(c_{2}(\gamma, \theta)\right) \text { for any } \gamma, \theta
$$

This implies that time-consistent agents are able to smooth consumption between work and retirement periods. This is because there is no additional uncertainty beyond $t=1$, so the government does not face informational constraints in the future. As a result, there is no need to distort the intertemporal margin at $t=1$.

From the government's perspective, present-biased agents save too little for their retirement. In essence, if present-biased agents were allowed to save freely, then $\frac{u^{\prime}\left(c_{1}(\gamma, \theta)\right)}{u^{\prime}\left(c_{2}(\gamma, \theta)\right)}=\beta$, so the intertemporal wedge is $\tau_{1}^{k}(\gamma, \theta)=1-\beta>0$ for any type $(\gamma, \theta)$. In contrast, the optimal policy by (3) and (4) recommends that the intertemporal wedge $\tau_{1}^{k}$ depends on the innate ability $\gamma$ and productivity $\theta$ of agents. This is because when agents are present biased, the introduction of an intertemporal wedge in $t=1$ that depends on $(\gamma, \theta)$ relaxes ex-ante incentive constraint. At $t=0$, agents are concerned that their future-selves would not save enough at $t=1$. By introducing a wedge that is a function of $(\gamma, \theta)$ in the agents' retirement savings decision, the government is able to influence the incentives for education attainment.

More specifically, by (3), we immediately notice that

$$
\frac{u^{\prime}\left(c_{1}(H, \theta)\right)}{u^{\prime}\left(c_{2}(H, \theta)\right)}>\beta .
$$

\footnotetext{
${ }^{2}$ Grochulski and Piskorski (2010) found that the inverse marginal utility of consumption is a strict supermartingale when agents are time consistent and ex-ante identical. In their paper, human capital investments are unobservable, so under investing in education is complementary to shirking in future periods. Hence, in addition to the usual distortion to deter over-saving, the optimal policy makes the intertemporal distortion worse at the education stage to deter under-investing in education. If education investment was observable in their environment, like ours, then the intertemporal distortion disappears.
} 
In other words, the government helps the high-educated agents save for retirement. The government essentially rewards high-educated agents with a commitment device that helps them smooth consumption across work and retirement. This commitment device substitutes part of the information rent to $H$-agents and relaxes the ex-ante incentive constraint.

By (4), for low-educated agents, the marginal rate of intertemporal substitution is

$$
\frac{u^{\prime}\left(c_{1}(L, \theta)\right)}{u^{\prime}\left(c_{2}(L, \theta)\right)} \begin{cases}>\beta & \text { if } \pi_{L}>\beta \mu \frac{f\left(\theta \mid \kappa_{L}, H\right.}{f\left(\theta \mid \kappa_{L}\right)} \\ =\beta & \text { if } \pi_{L}=\beta \mu \frac{f\left(\theta \mid \kappa_{L}, H\right.}{f\left(\theta \mid \kappa_{L}\right)} \\ <\beta & \text { if } \pi_{L}<\beta \mu \frac{f\left(\theta \mid \kappa_{L, H}\right)}{f\left(\theta \mid \kappa_{L}\right)}\end{cases}
$$

By (6), retirement savings for low-educated agents depend on the likelihood ratio $\frac{f\left(\theta \mid \kappa_{L, H}\right)}{f\left(\theta \mid \kappa_{L}\right)}$. In particular, if $\frac{f\left(\theta \mid \kappa_{L, H}\right)}{f\left(\theta \mid \kappa_{L}\right)}$ is relatively large, meaning that the observed productivity is likely to have come from a low-educated agent with high innate ability, then it is optimal to distort the retirement savings such that the present bias is exacerbated. The government uses this additional intertemporal distortion to deter the $H$-agents from under-investing in education. On the other hand, if $\frac{f\left(\theta \mid \kappa_{L, H}\right)}{f\left(\theta \mid \kappa_{L}\right)}$ is relatively small, meaning that the observed productivity is unlikely to have come from a low-educated agent with high-innate ability, then the government helps offset the present bias.

Assumption $1 f$ satisfies the monotone likelihood ratio property: $\frac{f(\theta \mid \kappa)}{f\left(\theta \mid \kappa^{\prime}\right)}$ is increasing in $\theta$ for any $\kappa>\kappa^{\prime}$.

Assumption 1 implies that high productivity is more likely to come from higher accumulated human capital. With Assumption 1, the optimal intertemporal wedge for low-educated agents increases with productivity. As a result, the government helps the low-educated agents who are less productive with their retirement savings, while the retirement savings of loweducated agents who are highly productive are restricted. This is because Assumption 1 implies that $H$-agents who do not invest in higher education are more likely than $L$-agents to be productive. As a result, the government exacerbates the present bias of low-educated and productive agents to relax the ex-ante incentive constraint and encourage $H$-agents to increase education attainment. We assume Assumption 1 holds for the rest of the paper. ${ }^{3}$

It is worth noting that the additional intertemporal distortion $\tau_{1}^{k}$ is caused by the fact that $\gamma$ is the private information of present-biased agents. If the government can observe $\gamma$, then the standard Euler equation would hold: $u^{\prime}\left(c_{1}(\gamma, \theta)\right)=u^{\prime}\left(c_{2}(\gamma, \theta)\right)$ for any $\gamma$ and $\theta$. As

\footnotetext{
${ }^{3}$ The monotone likelihood ratio property implies first order stochastic dominance.
} 
was mentioned before, if agents were time-consistent, then the standard Euler equation for $t=1$ also holds. As a result, the intertemporal wedge $\tau_{1}^{k}$ is solely used to relax the ex-ante incentive compatibility constraint of present-biased agents.

Also, if productivity $\theta$ is a deterministic function of human capital $\kappa$, then there will also be no intertemporal distortions. In other words, if human capital investment is riskless, then the government does not need to introduce any intertemporal distortions. In fact, Yu (2018a) showed that the government can implement the full-information efficient optimum when there is no dynamic private information through the use of off-path policies.

\subsection{Labor Wedge}

The dynamic incentive problem and the agents' present bias also affects the labor wedge and the optimal marginal income tax rate. To separate the economic forces that determine the optimal labor distortions, we define

$$
\begin{aligned}
& A_{\gamma}(\theta)=\frac{1-F\left(\theta \mid \kappa_{\gamma}\right)}{\theta f\left(\theta \mid \kappa_{\gamma}\right)}, \\
& B_{\gamma}(\theta)=1+\frac{\frac{y(\gamma, \theta)}{\theta} h^{\prime \prime}\left(\frac{y(\gamma, \theta)}{\theta}\right)}{h^{\prime}\left(\frac{y(\gamma, \theta)}{\theta}\right)}, \\
& \left.C_{\gamma}(\theta)=\int_{\theta}^{\bar{\theta}} \frac{u^{\prime}\left(c_{1}(\gamma, \theta)\right)}{u^{\prime}\left(c_{1}(\gamma, x)\right)}\left[1-\frac{u^{\prime}\left(c_{1}(\gamma, x)\right)}{\phi}\right] \frac{f\left(x \mid \kappa_{\gamma}\right)}{1-F\left(\theta \mid \kappa_{\gamma}\right)} d x, \frac{1}{\phi}\right], \\
& D_{\gamma}(\theta)=u^{\prime}\left(c_{1}(\gamma, \theta)\right)\left[\frac{1}{u^{\prime}\left(c_{0}(\gamma)\right)}-\frac{u^{\prime}\left(c_{1}(\gamma, \theta)\right)}{\phi}\right. \\
& E_{\gamma}(\theta)=\left[\frac{u^{\prime}\left(c_{1}(\gamma, \theta)\right)}{\beta u^{\prime}\left(c_{2}(\gamma, \theta)\right)}-1\right]-\left(\frac{1-\beta}{\beta}\right)
\end{aligned}
$$

where $\phi>0$ is the shadow price on the resource constraint.

Proposition 2 The labor wedge for each level of education attainment and $\theta \in \Theta$ satisfies

$$
\begin{gathered}
\frac{\tau^{w}(H, \theta)}{1-\tau^{w}(H, \theta)}=A_{H}(\theta) B_{H}(\theta)\left[C_{H}(\theta)-D_{H}(\theta)+E_{H}(\theta)\right], \\
\frac{\tau^{w}(L, \theta)}{1-\tau^{w}(L, \theta)}=A_{L}(\theta) B_{L}(\theta)\left[C_{L}(\theta)-\left(\frac{1-F\left(\theta \mid \kappa_{L, H}\right)}{1-F\left(\theta \mid \kappa_{L}\right)}\right) D_{L}(\theta)+\frac{h\left(\theta \mid \kappa_{L}\right)}{h\left(\theta \mid \kappa_{L, H}\right)} E_{L}(\theta)\right], \\
\text { where } h(\theta \mid \kappa)=\frac{f(\theta \mid \kappa)}{1-F(\theta \mid \kappa)} \text { and } \phi=\left\{\mathbb{E}_{\gamma}\left[\mathbb{E}_{\theta}\left(\frac{1}{u^{\prime}\left(c_{1}(\gamma, \theta)\right)} \mid \gamma\right)\right]\right\}^{-1} .
\end{gathered}
$$


Proposition 2 presents the optimal labor wedge for present-biased agents in a sequential screening environment. We can decompose the economic forces into three distinct components: intratemporal, intertemporal and present-bias components. Following Golosov et al. (2016), the intratemporal component summarizes the trade-offs in increasing labor distortions to insure against the productivity shock, while the intertemporal component captures how labor distortions affect the education decision in the previous period. Unique to our paper, the present-bias component encompasses the effects of time inconsistency on the optimal labor distortions. We rewrite (7) and (8) to pinpoint each component:

$$
\begin{gathered}
\frac{\tau^{w}(H, \theta)}{1-\tau^{w}(H, \theta)}=\underbrace{A_{H}(\theta) B_{H}(\theta) C_{H}(\theta)}_{\text {intratemporal component }}-\underbrace{A_{H}(\theta) B_{H}(\theta) D_{H}(\theta)}_{\text {intertemporal component }}+\underbrace{A_{H}(\theta) B_{H}(\theta) E_{H}(\theta)}_{\text {present-bias component }}, \\
\frac{\tau^{w}(L, \theta)}{1-\tau^{w}(L, \theta)}=\underbrace{A_{L}(\theta) B_{L}(\theta) C_{L}(\theta)}_{\text {intratemporal component }}-\underbrace{\left(\frac{1-F\left(\theta \mid \kappa_{L, H}\right)}{1-F\left(\theta \mid \kappa_{L}\right)}\right) A_{L}(\theta) B_{L}(\theta) D_{L}(\theta)}_{\text {intertemporal component }} \\
+\underbrace{\frac{h\left(\theta \mid \kappa_{L}\right)}{h\left(\theta \mid \kappa_{L, H}\right)} A_{L}(\theta) B_{L}(\theta) E_{L}(\theta)}_{\text {present-bias component }} .
\end{gathered}
$$

All components are affected by $A_{\gamma}(\theta)$ and $B_{\gamma}(\theta)$. To understand these terms, first note that by introducing a labor wedge for type $(\gamma, \theta)$ agents, their labor supply changes according to their Frisch elasticity of labor supply, which is $B_{\gamma}(\theta)$. Furthermore, an increase in the labor distortion for agents of type $(\gamma, \theta)$ decreases their total output in proportion to $\theta f(\theta \mid \kappa)$ while the incentive constraints for higher productivity agents with mass $1-F(\theta \mid \kappa)$ are relaxed. This trade-off is captured by $A_{\gamma}(\theta)$.

Without dynamic information, the optimal labor wedge is determined by the intratemporal component, which fully summarizes the economic forces in static models, such as Diamond (1998) and Saez (2001). In addition to $A_{\gamma}(\theta)$ and $B_{\gamma}(\theta)$, the intratemporal component also consists of $C_{\gamma}(\theta)$, which captures the strength of the government's insurance motive against the productivity shock. In the static Mirrlees, the inverse marginal utility is the cost in consumption terms of a marginal increase in utility, so the cost of a marginal increase in average utility in $t=1 \mathrm{is} \frac{1}{\phi}$. Hence, if the cost of increasing average utility is small relative to the cost of increasing the utility of $(\gamma, x)$ agents $\left(\frac{u^{\prime}\left(c_{1}(\gamma, x)\right)}{\phi}<1\right)$, then the benefits of increasing the labor wedge to relax the incentive constraints of $x \geq \theta$ types and raise transfers to lower productivity types outweighs the cost, so $C_{\gamma}(\theta)$ is positive. Furthermore, the degree of labor distortion increases with consumption inequality, which is represented by 
$\frac{u^{\prime}\left(c_{1}(\gamma, \theta)\right)}{u^{\prime}\left(c_{1}(\gamma, x)\right)}$. Observe that the forces influencing the intratemporal component are independent of the agents' ex-ante type $\gamma$.

When there is dynamic information and agents are time-consistent, then the labor wedge is shaped by both the intratemporal and intertemporal components. This is similar to the labor distortions in Findeisen and Sachs (2016). The intertemporal component contains the term $D_{\gamma}(\theta)$ and is augmented by $\frac{1-F\left(\theta \mid \kappa_{L, H}\right)}{1-F\left(\theta \mid \kappa_{L}\right)}$ for $L$-agents. Notice that $D_{\gamma}(\theta)$ can be rewritten as $\frac{\left[u^{\prime}\left(c_{0}(\gamma)\right)\right]^{-1}-\phi^{-1}}{\left[u^{\prime}\left(c_{1}(\gamma, \theta)\right)\right]^{-1}}$, so $D_{H}(\theta)>0$ and $D_{L}(\theta)<0$. Therefore, since the cost of raising utility in $t=0$ is relatively large for $H$-agents, the government can encourage investment in education through promising a smaller labor wedge $\tau^{w}(H, \theta)$ rather than increasing $c_{0}(H)$. Furthermore, the government also provides dynamic incentives by exploiting the fact that agents with human capital $\kappa_{L, H}$ are likely to have higher productivity than $\kappa_{L}$ agents. As a result, $\frac{1-F\left(\theta \mid \kappa_{L, H}\right)}{1-F\left(\theta \mid \kappa_{L}\right)}$ captures how the optimal labor distortion for non-college grads leverages the difference in distribution of productivity for agents of differing innate ability $\gamma$.

When agents are present biased, the present-bias component highlights the additional force that influences the labor wedge. The present-bias component is comprised of two potentially off-setting forces: the disagreement and myopic components,

$$
E_{\gamma}(\theta)=\underbrace{\left[\frac{u^{\prime}\left(c_{1}(\gamma, \theta)\right)}{\beta u^{\prime}\left(c_{2}(\gamma, \theta)\right)}-1\right]}_{\text {disagreement component }}-\underbrace{\left(\frac{1-\beta)}{\beta}\right) \frac{u^{\prime}\left(c_{1}(\gamma, \theta)\right)}{\phi}}_{\text {myopic component }} .
$$

The disagreement component characterizes how the labor distortion is affected by the government's commitment to retirement savings. The myopic component captures the fact that present-biased agents do not fully internalize the returns from working. Observe that when $\beta=1$, the intertemporal wedge at $t=1$ is zero so $E_{\gamma}(\theta)=0$ for any $\gamma$ and $\theta$.

To see the intuition of the disagreement component, recall from Proposition 1, we showed how the government provides $H$-agents with commitment in $t=1$ to relax the ex-ante incentive constraints. It also provides commitment to $L$-agents conditional on their realized productivity. However, from the present-biased agents' perspective in $t=1$, the optimal consumption path satisfies $u^{\prime}\left(c_{1}\right)=\beta u^{\prime}\left(c_{2}\right)$. Hence, the commitment the government provides is perceived as an intertemporal distortion to agents in $t=1$, which distorts their labor supply by decreasing their incentives to work. This is reflected in the disagreement component which increases the labor wedge when the government provides more commitment.

As for the myopic component, note that increased output is rewarded with more consumption in both $t=1$ and $t=2$. However, present-biased agents under-estimate the benefits of work, because they discount retirement consumption. As a result, the myopic component shows how the optimal labor wedge is decreased to correct for the tendency of 
present-biased agents to undervalue the rewards for effort. Furthermore, due to insurance motives, the myopic component has the labor distortion inversely related to working-period consumption, so less productive agents receive more help in internalizing the benefits of working. The optimal labor wedge in Lockwood (2016) also contains a similar economic force as the myopic component. However, Lockwood (2016) does not consider consumption dynamics, so the disagreement component is absent in his characterization.

Furthermore, the present-bias component for $L$-agents is amplified by the hazard rate ratio $\frac{h\left(\theta \mid \kappa_{L}\right)}{h\left(\theta \mid \kappa_{L, H}\right)}$, which is greater than 1 by Assumption $1 .{ }^{4}$ Again, this shows how the government uses the difference in productivity distribution for agents with varying innate abilities to relax the ex-ante incentive constraint. Lastly, notice that the myopic component always decreases the labor distortion, while the disagreement component usually increases it unless the government does not provide commitment: $\frac{u^{\prime}\left(c_{1}\right)}{u^{\prime}\left(c_{2}\right)}<\beta$. As a result, the impact of the present-bias component on the optimal labor wedge is unclear.

Since most of the components are composed of endogenous variables, we rely on our quantitative exercise to characterize the labor wedge. Appendix C quantifies the decomposition of the optimal labor wedge. As we show there, the shape of the labor wedge is mostly determined by our assumptions on the distribution of skills and the size of the intratemporal component. By contrast, the present bias component plays a minor role quantitatively.

\section{Quantitative Analysis}

In this section, we quantify the model by imposing specific functional forms and calibrating their parameters. Then, we measure the quantitative significance of the theoretical results presented in Section 3, as well as the potential welfare gains under the optimal tax system.

Table 1 presents the calibrated parameter values. We select the standard functional forms for the utility of consumption $u(c)=\frac{c^{1-\sigma}}{1-\sigma}$ and the disutility of labor $h(\ell)=\frac{\ell^{1+\frac{1}{\eta}}}{1+\frac{1}{\eta}}$, and we assume they are constant over time. The risk aversion and the Frisch elasticity of labor supply are then set to standard values of 2 and 0.5 , respectively. The share of low types (high school only graduates) is 0.64 following Cunha and Heckman (2007). The short- and long-run discount factors are calibrated based on the values proposed by Nakajima (2012). The short-term discount factor is 0.7 , in the ballpark of the empirical estimates of Laibson et al. (2017). The long-run discount factors are based on the annual rate of 0.9852 and compounded to take into account the relative length of different periods. We assume that $t=0$ begins at age 18 and lasts 4 years in the case of college graduates, or 0 years otherwise

\footnotetext{
${ }^{4}$ Assumption 1 also implies hazard rate dominance: $h(\theta \mid \kappa) \leq h\left(\theta \mid \kappa^{\prime}\right)$ for all $\theta$ when $\kappa>\kappa^{\prime}$.
} 
(hence, $\left.\delta_{0}\left(e_{L}\right)=0\right)$. Agents work for 45 years, upon which they retire and live for 20 years in retirement. Section B.2 in the Appendix discusses more details of this calibration procedure. In the subsequent analysis we will also make comparisons with a variant of our model for time-consistent agents (i.e. $\beta=1$ ). In that case, following Nakajima (2012), we recalibrate the effective discount factors based on the annual rate of 0.9698 . The purpose of such a recalibration is to separate the effect of time-inconsistency in agents' behavior from their effectively increased impatience.

Table 1: Parameter values in the model

\begin{tabular}{lll}
\hline Symbol & Meaning & Value \\
\hline$\pi_{0}(L)$ & Share of low type & 0.64 \\
$\pi_{0}(H)$ & Share of high type & 0.36 \\
$\sigma$ & Risk aversion & 2 \\
$\eta$ & Frisch elasticity & 0.5
\end{tabular}

Discount factors: present bias

$\begin{array}{lll}\beta & \text { Short-term discount factor } & 0.7 \\ \delta_{0}(L) & \text { High school period 0 long-term discount factor } & 0.00 \\ \delta_{1}(L) & \text { High school period 1 long-term discount factor } & 1.00 \\ \delta_{0}(H) & \text { College period 0 long-term discount factor } & 0.118 \\ \delta_{1}(H) & \text { College period 1 long-term discount factor } & 0.942 \\ \delta_{2} & \text { Retirement discount factor } & 0.254\end{array}$

Discount factors: time-consistent benchmark

\begin{tabular}{lll}
\hline$\delta_{0}(L)$ & High school period 0 long-term discount factor & 0.00 \\
$\delta_{1}(L)$ & High school period 1 long-term discount factor & 1.00 \\
$\delta_{0}(H)$ & College period 0 long-term discount factor & 0.154 \\
$\delta_{1}(H)$ & College period 1 long-term discount factor & 0.885 \\
$\delta_{2}$ & Retirement discount factor & 0.154 \\
\hline
\end{tabular}

In order to calibrate the distributions of skills for the agents differing in innate ability and education, we create a separate model which we refer to as the "current policies" world. This model is described in detail in Appendix B. We take this model to the data, solve for optimal behavior and simulate large population of agents from each of the four groups: (i.) factual high school graduates, (ii.) high school graduates, had they gone to college, (iii.) factual college graduates, and (iv.) college graduates, had they not gone to college. We select the parameters governing the distributions of skills such that the simulated distribution of lifetime earnings for each group matches the one reported by Cunha and Heckman (2007). In particular, this study uses a variation of the Roy model to infer counterfactual distributions 
of earnings for both high school and college graduates had they made the opposite education decision. Also, to correct for the under-representation of high-end earnings in the data, we add an upper Pareto-tail to each distribution such that the upper $10 \%$ of the mass is distributed according to a shape parameter of 1.5, as in Saez (2001). Figure 1 presents the four distributions backed out as a result of this procedure.

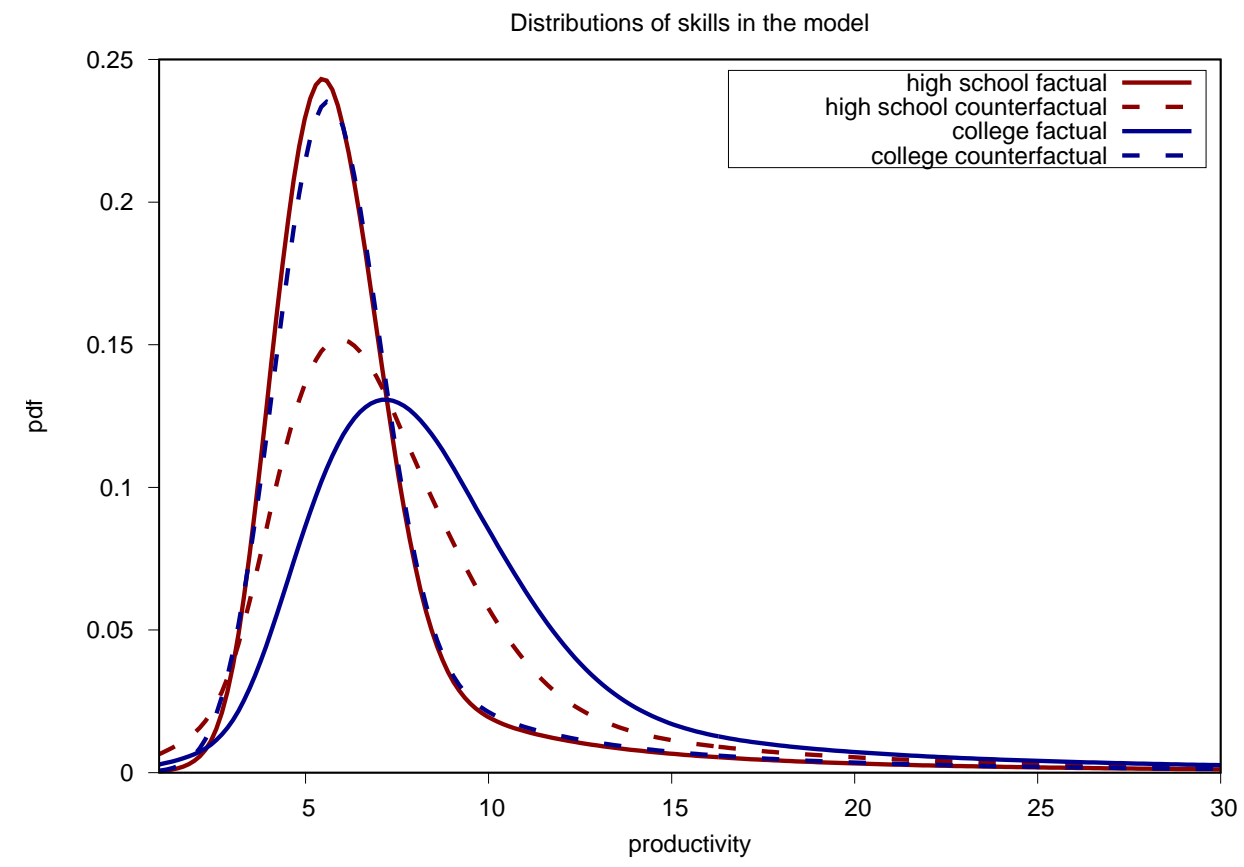

Figure 1: Calibrated distributions of skills for the four groups of agents

In what follows, we discuss our quantitative results. We begin with Table 2 which shows the optimal savings wedge in $t=0$. In line with the hallmark dynamic Mirrlees result, the government finds it optimal to tax savings in $t=0$ in order to induce higher labor effort from agents in the next period. Notice also that the optimal wedge amounts are similar to the model with time-consistent agents, which is a product of our calibration that holds the effective discount factor constant across the two models. Importantly though, the wedge for present-biased agents is slightly higher, raising the consumption of college students and providing additional incentive to make the college investment. ${ }^{5}$

Table 2: Capital wedge period zero: present-bias vs. time-consistent case

\begin{tabular}{lcc}
\hline & Present-biased & Time-consistent \\
\cline { 2 - 3 }$\tau_{0}^{k}(H)$ & 0.3209 & 0.2734 \\
\hline
\end{tabular}

\footnotetext{
${ }^{5}$ The savings wedge for $L$-agents $\tau_{0}^{k}(L)$ is not shown since for our quantitative exercise, we assumed $L$-agents do not have a student period $\left(\delta_{0}\left(e_{L}\right)=0\right)$.
} 
Figure 2 shows the optimal savings wedges in $t=1$ and conveys a key quantitative result. The wedges are negative for a wide interval of low lifetime incomes (where the unit is $\$ 10,000)$, and are always lower than $1-\beta$, which implies that the government offers savings subsidies. ${ }^{6}$ This is an expected outcome in a model with paternalistic policies and agents who suffer from present bias. More importantly, the wedges are significantly different for the two education groups. College graduates enjoy a much higher subsidy than high school graduates at all income levels, with the difference eventually disappearing for higher incomes. The government does so in order to provide them with incentives to invest in college education ex-ante. Without such incentives, $H$-agents worry that additional education will not deliver a sufficient increase in their welfare, because their own present bias will prevent them from smoothing their higher working-age income across the life cycle. By contrast, notice that in the variant of our model with time-consistent agents, the optimal capital wedge in the working-age period is equal to zero for both education groups. This is because time-consistent agents are able to raise retirement savings on their own.

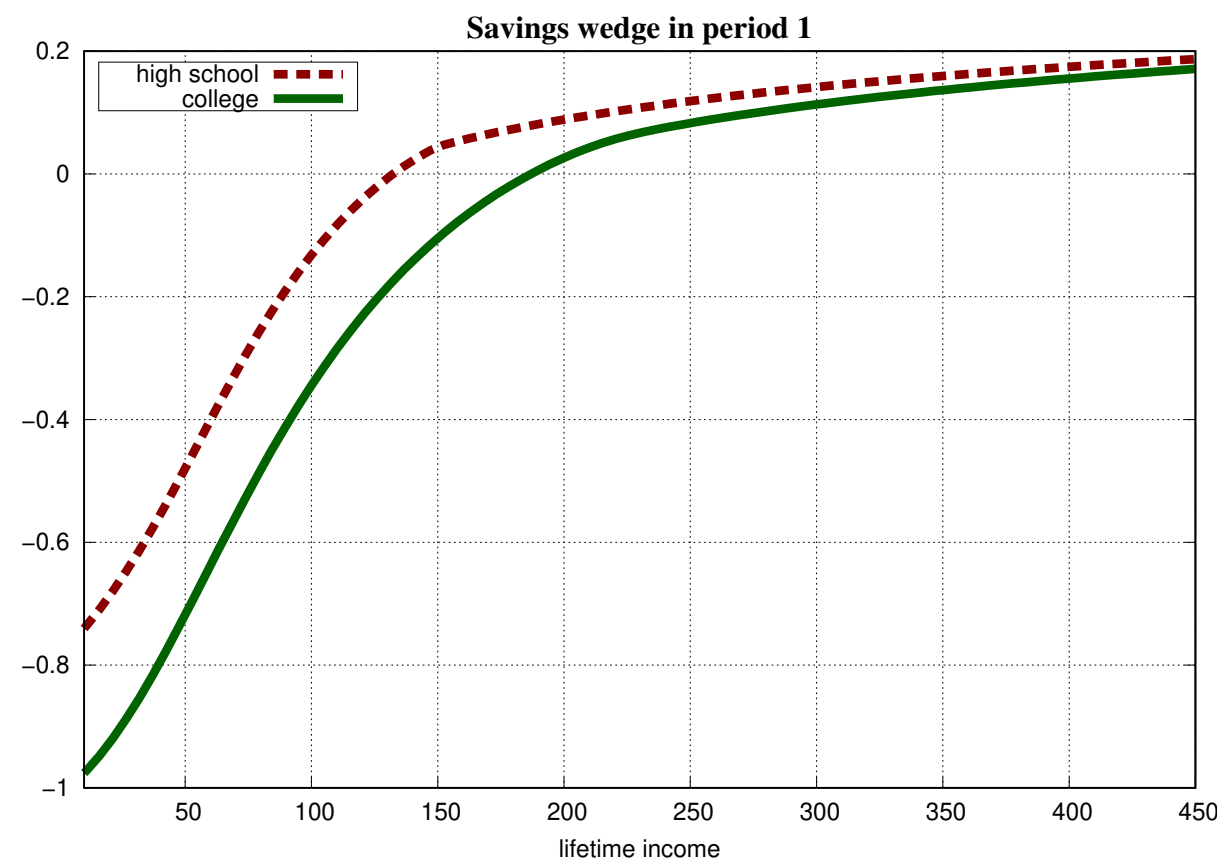

Figure 2: Savings wedge in the model with present-biased agents

Figure 3 presents the optimal labor wedges for both education groups according to the two variants of our model: with present-biased agents or with time-consistent agents. The optimal labor wedges follow a U-shaped pattern and converge to a constant for top incomes

\footnotetext{
${ }^{6}$ The theoretical result where the government decreases savings for sufficiently high $\theta$ is not quantitatively significant since the distributions $f(\theta \mid \kappa)$ and $f\left(\theta \mid \kappa_{L, H}\right)$ are similar.
} 
levels, which is standard in Mirrlees taxation with Pareto-tailed productivity distributions (Diamond, 1998; Saez, 2001). The main thing to notice is that optimal wedges mostly decline with income and are significantly different for the two education groups. This resembles the main result of Findeisen and Sachs (2016) and stems from the fact that high innate ability agents must be offered a separate income tax schedule to provide them with incentives to optimally choose to go to college. Notice that the differences in optimal wedges between the present-biased and time-consistent settings are very small, and arise predominantly at the lowest income levels. This implies that the presence of present-biased agents does not alter the normative prescriptions in terms of the design of income tax schedules that the literature has established so far. Appendix $\mathrm{C}$ reinforces this point by showing that the present-bias component of the optimal labor wedge, as introduced in Section 3.2, is in general small quantitatively and declines monotonically with income. This is in contrast to a setting without dynamic consumption, where marginal income tax rates could become negative (Lockwood, 2016).

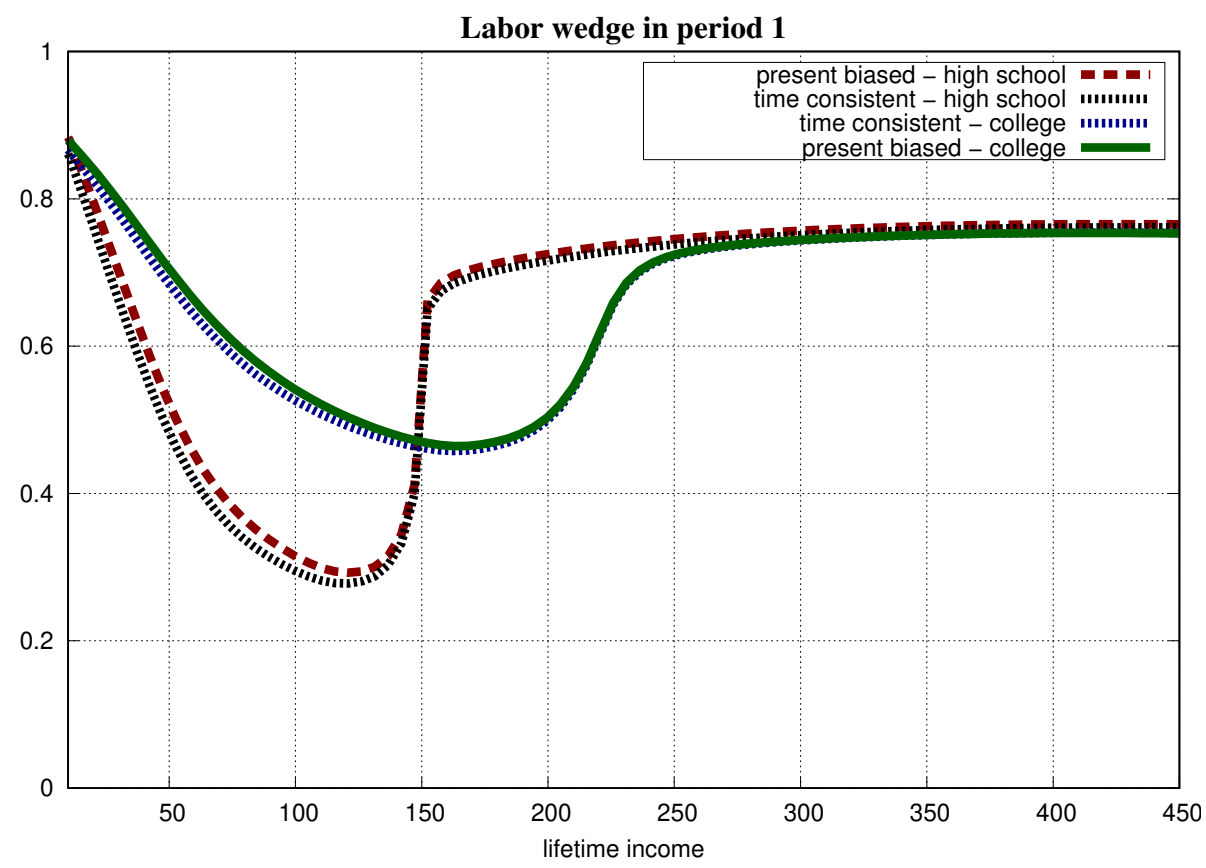

Figure 3: Labor wedge in the model with present biased agents

\subsection{Welfare gains from optimal policies}

We now turn our attention to the calculation of potential welfare gains arising from the optimal policies. We compare our optimum to optimal policies for time-consistent agents. 
We consider two possible policy implementations for time-consistent agents. ${ }^{7}$ The first one, called the laissez-faire implementation, leaves the agents alone in their retirement savings decision in period $t=1$. Because the policy is dedicated for time-consistent agent, the government is confident that agents will smooth consumption in line with their time preferences. This is not the case for present-biased agents though, and hence we expect our optimal policies to bring about significant welfare gains relative to this benchmark.

In order to isolate the effect of education-dependent savings incentives from mere subsidization of retirement savings, we also consider an implementation of the benchmark that features mandatory savings. In this world, agents are forced to smooth their consumption between working-life and retirement in line with the Euler equation. It does not make a difference for time-consistent agents who would have made the same choice anyway. On the other hand, present-biased agents will be affected in that the government will help them save for retirement, but without taking advantage of the education-dependent capital wedge.

Table 3: Welfare gains over optimal policies for time-consistent agents

\begin{tabular}{lcc}
\hline & Mandatory savings & Laissez-faire \\
\cline { 2 - 3 }$\%$ increase in lifetime consumption & 1.12 & 1.18 \\
\hline
\end{tabular}

Table 3 presents the welfare gains under our baseline parametrization relative to the two time-consistent benchmarks. Consistent with prior expectations, the gains over laissez-faire policies are the highest and amount to $1.18 \%$ of lifetime consumption. The gains come from increased retirement savings and also from improved production efficiency. On the other hand, the gains relative to mandatory savings is $1.12 \%$ of lifetime consumption, which is close to the welfare gains over laissez-faire policies. Since mandatory savings policy already forces agents to smooth their consumption, this implies the welfare gains of the optimal education-dependent policies largely come from more efficient production.

\section{Implementation}

After characterizing the wedges, we are ready to explore the implications of our findings on the design of student loans, income taxes and retirement policies. In particular, this section highlights how to decentralize retirement savings policies for individuals paying off their student loans, which is the main innovation of the paper.

For education policies, we consider a decentralization with student loans and incomecontingent repayment plans. Agents can take out a loan amount of $L(e)$, which is a function

\footnotetext{
${ }^{7}$ The details of these implementations are presented in Appendix D.
} 
of the education expenses. After agents enter the work force, the loan repayment is a function of realized income and education expenses.

For retirement savings, we consider two ways of implementing the optimum. First, we present an implementation where the subsidy for retirement savings is both income and education contingent. Finally, we examine an implementation with social security and a retirement savings account where student loan repayments are also considered as contributions to the account. The latter implementation is inspired by the recently proposed bill in the US Congress called the Retirement Parity for Student Loans Act, which intends to qualify student loan repayments for employer matching.

Before presenting the decentralized economy, it is important to note that we are departing from the direct revelation mechanism in which agents report their innate ability $\gamma$ and productivity $\theta$. Instead, policies are based on the observed education expense $e$, income $y$ and savings. Since policies are a function of observed income and education decisions, we first show that the optimal consumption from the direct revelation mechanism $\left\{c_{0}(\gamma), c_{t}(\gamma, \theta)\right\}_{\gamma, t>0, \theta \in \Theta}$ can be expressed as a function of income $y(\gamma, \theta)$ and education $e_{\gamma}$. It is clear that if the condition of Lemma 2 holds, then it is optimal to separate agents based on innate ability $\gamma$. Therefore, the optimal allocations can be rewritten as a function of education instead of reported innate ability, so $c_{0}(\gamma)=c_{0}\left(e_{\gamma}\right)$ and $c_{t}(\gamma, \theta)=c_{t}\left(e_{\gamma}, \theta\right)$. The next lemma shows that reported productivity $\theta$ can be replaced with income, so the government can implement the optimum using policies that depend on income and education.

Lemma 3 For any $e \in\left\{e_{L}, e_{H}\right\}$, the optimal consumption $c_{1}(e, \theta)$ and $c_{2}(e, \theta)$ are functions of $y(e, \theta)$, so $c_{t}(e, \theta)=c_{t}(y(e, \theta))$ for any $t>1$.

\subsection{Education-Contingent Retirement Savings Subsidy}

For our first implementation, the agent is offered a student loan $L(e)$ in $t=0$, and is required to make an income contingent repayment $r(e, y)=\left[1-\tau^{e}(e, y)\right] L(e)$ in $t=1$, where the subsidy $\tau^{e}(e, y)$ is a function of past education expenses and income. In $t=1$, agents also face an income tax $T(y)$ independent of education. Most importantly, agents can save $s_{2}$ in a retirement account at $t=1$, where retirement savings are subsidized at a rate $\tau^{s}(e, y)$ which is a function of income and past education investment. Furthermore, retirement savings $s_{2}$ come from after-tax funds, so the income and education dependent retirement savings account is similar to a Roth 401(k). Finally, in each period, agents can save via the risk-free bond $b$, which are taxed with a bond savings $\operatorname{tax} T^{k}(b)$.

Given the proposed policies, at $t=1$, agents with education level $e$ and productivity $\theta$ 
solve the following:

$$
\max _{c_{1}, y, c_{2}}\left\{u\left(c_{1}\right)-h\left(\frac{y}{\theta}\right)+\beta \delta_{2} u\left(c_{2}\right)\right\}
$$

subject to

$$
\begin{gathered}
c_{1}+s_{2}+b_{2}+R_{1}(e)\left(1-\tau^{e}(e, y)\right) L(e)=y-T(y)+R_{1}(e) b_{1}-T^{k}\left(b_{2}\right), \\
c_{2}=R_{2}\left(1+\tau^{s}(e, y)\right) s_{2}+R_{2} b_{2} .
\end{gathered}
$$

Let $\left\{c_{1}^{*}(e, \theta), y^{*}(e, \theta), c_{2}^{*}(e, \theta)\right\}$ denote the solution to the agents' problem at $t=1$ for any $\theta \in \Theta$ and $e \in\left\{e_{L}, e_{H}\right\}$. Also, let $U_{1}(e, \theta)$ denote the value function for the agents' problem at $t=1$. The agents' problem with innate ability $\gamma$ at $t=0$ is

$$
\max _{c_{0}, e}\left\{\delta_{0}(e) u\left(c_{0}\right)+\beta \delta_{1}(e) \int_{\underline{\theta}}^{\bar{\theta}}\left[U_{1}(e, \theta)+(1-\beta) \delta_{2} u\left(c_{2}^{*}(e, \theta)\right)\right] f(\theta \mid \kappa(e, \gamma)) d \theta\right\}
$$

subject to

$$
c_{0}+e+b_{1}=L(e)-T^{k}\left(b_{1}\right) \text { and } e \in\left\{e_{L}, e_{H}\right\} .
$$

Let $P^{s s}=\left\{\left[L(e), \tau^{e}(e, y)\right], \tau^{e}(e, y),\left[T(y), T^{k}(b)\right]\right\}$. The following proposition states that the optimum can be decentralized with an income-contingent student loans policy $\left(L(e), \tau^{e}(e, y)\right)$ combined with an income and education dependent retirement subsidy $\tau^{s}(e, y)$ and tax policy $\left(T(y), T^{k}(b)\right)$.

Proposition 3 The optimum can be implemented with $P^{s s}$.

Figure 4 presents the optimal student loan repayment and retirement savings subsidies for the two education groups as function of income. Panel 4(a) shows that for the agents with income below 1,250,000 in present value, the repayment subsidy starts at over $80 \%$ and decreases with income, at some point turning into a tax. Once the Pareto tail kicks in, the trend reverts and the optimal subsidy increases before settling at around 60\%. Panel 4(b) shows the savings subsidy schedules. Notice that the optimal subsidies closely mirror the savings wedges $\tau_{1}^{k}$ depicted in Figure 2, where lower income levels receive more subsidies and the subsidy for college graduates is higher for virtually all income levels.

It is worth pointing out that the optimal student loans subsidy is determined by the labor wedges. We set the income tax to match the labor wedge for $L$-agents, while the income contingent student loans subsidies coupled with the marginal income tax rate replicates the optimal labor wedge for $\mathrm{H}$-agents. Since the optimal labor wedge for $\mathrm{H}$-agents is larger with the difference growing until income 1,250,000, the student loans subsidy is decreasing up to that amount. Beyond 1,250,000, the difference in the labor wedges decreases initially 


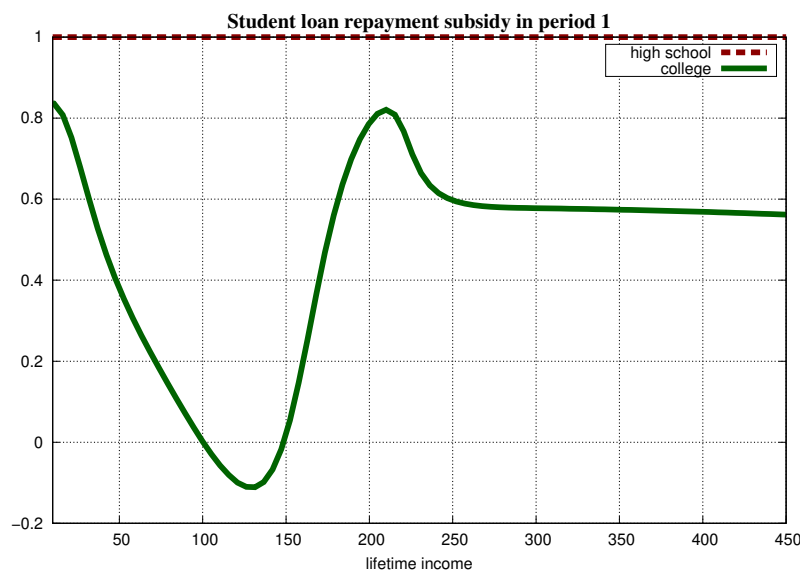

(a) Optimal student loan subsidy $\tau^{e}(e, y)$

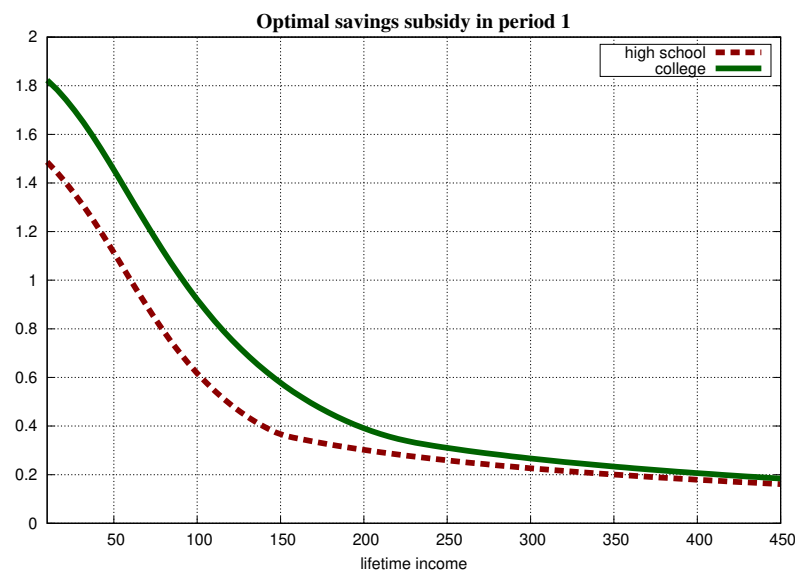

(b) Optimal savings subsidy $\tau^{s}(e, y)$

Figure 4: Optimal education-contingent subsidies

and with the optimal labor wedge for $L$-agents eventually rising above the labor wedge of $H$-agents, which causes the student loans subsidy to increase. Also, since we appended the Pareto-tail to the top $10 \%$ of the productivity distribution for each education group, the $U$-shaped dip in the labor wedge for $H$-agents is much higher than the one for $L$-agents. As a result, the labor wedge for $L$-agents is much larger than the labor wedge for $H$-agents between lifetime incomes 1,500,000 and 2,250,000. This drives the significant increase in student loans subsidy beyond 1,250,000.

\subsection{Student Loan Payment as Contribution to Retirement Savings}

Here, we consider an alternative implementation with social security benefits and retirement savings accounts. All agents receive an income-contingent social security benefit $a(y)$ upon retirement. The retirement savings account is defined by the contribution matching rate $\alpha \in[0,1]$ and a contribution limit $\bar{s}$. The amount of student loan repaid $R_{1}(e) r(e, y)$ is considered a contribution, so employers can further contribute $\alpha R_{1}(e) r(e, y)$ into the account. Except for the changes in the retirement savings account and the introduction of social security, the economic environment is similar to the previous implementation.

The advantage of this decentralization is that it uses existing policies, except for the introduction of an education-dependent retirement savings account, which deposits a fraction of student loans repayment into the retirement account. This new feature is appealing since there exist discussions on retirement savings policies contingent on student loan repayments. In particular, the recent ruling of the IRS states that employers can contribute to the retirement account as long as individuals are paying off their student loans, and the US Congress 
is currently considering enacting this into law.

Let $\phi\left(s_{2}, r\right)$ denote the amount of assets in the retirement savings account as a function of the deposit $s_{2}$ and the student loan repayment $r$, so we have

$$
\phi\left(s_{2}, r\right)=(1+\alpha) s_{2}+\alpha R_{1}(e) r .
$$

The student loan repayment is tax deductible and reduces income tax by $g\left(R_{1} r\right)$. Given the proposed policies, at $t=1$, agents with education investment $e$ and productivity $\theta$ solve

$$
\max _{c_{1}, y, c_{2}}\left\{u\left(c_{1}\right)-h\left(\frac{y}{\theta}\right)+\beta \delta_{2} u\left(c_{2}\right)\right\}
$$

subject to

$$
\begin{gathered}
c_{1}+s_{2}+b_{2}+R_{1}(e) r(e, y)=y-T\left(y-s_{2}\right)+g\left(R_{1}(e) r(e, y)\right)+R_{1}(e) b_{1}-T^{k}\left(b_{2}\right), \\
c_{2}=a(y)+R_{2} \phi\left(s_{2}, r(e, y)\right)+R_{2} b_{2}-\mathbf{1}_{\phi>0} T^{r a}, \\
0 \leq s_{2} \leq \bar{s},
\end{gathered}
$$

where $\mathbf{1}_{\phi>0}=1$ if and only if there are assets in the account, otherwise $\mathbf{1}_{\phi>0}=0$. Notice that retirement account contributions come from pre-tax income and are only lump-sum taxed $T^{r a}$ upon withdrawal, so the retirement savings account is similar to a traditional 401(k). Furthermore, similar to current retirement saving accounts, matched contributions are not subject to the contribution limit $\bar{s}$. Adopting the notation introduced in the previous implementation, the agents' problem with innate ability $\gamma$ at $t=0$ is

$$
\max _{c_{0}, e}\left\{\delta_{0}(e) u\left(c_{0}\right)+\beta \delta_{1}(e) \int_{\underline{\theta}}^{\bar{\theta}}\left[U_{1}(e, \theta)+(1-\beta) \delta_{2} u\left(c_{2}^{*}(e, \theta)\right)\right] f(\theta \mid \kappa(e, \gamma)) d \theta\right\}
$$

subject to

$$
c_{0}+e+b_{1}=L(e)-T^{k}\left(b_{1}\right) \text { and } e \in\left\{e_{L}, e_{H}\right\} .
$$

Let $P^{r a}=\left\{[L(e), r(e, y)], a(y),[\alpha, \bar{s}],\left[T(y), T^{k}(b), T^{r a}, g\left(R_{1} r\right)\right]\right\}$ denote the policy instruments for the proposed implementation. The following proposition shows that it is possible to decentralize the optimum using $P^{r a}$.

Proposition 4 The optimum can be implemented through $P^{\text {ra }}$ where student loan repayments are considered contributions to the retirement savings account.

Figure 5 presents the student loan repayment schedule in our second implementation. The solid green line shows the face value of the repayment which starts high and then decreases 
initially, allowing college-graduates to accumulate additional (and decreasing in income) contributions in their 401(k) plans. In order to maintain the optimal income-contingency in loan repayments, these agents are offered the tax deduction, which makes their repayment schedule increase in income, as represented by the dashed red line. Notice that once the Pareto tail for high school graduates kicks in (around 1,500,000 of present value of lifetime income), the two trends revert.

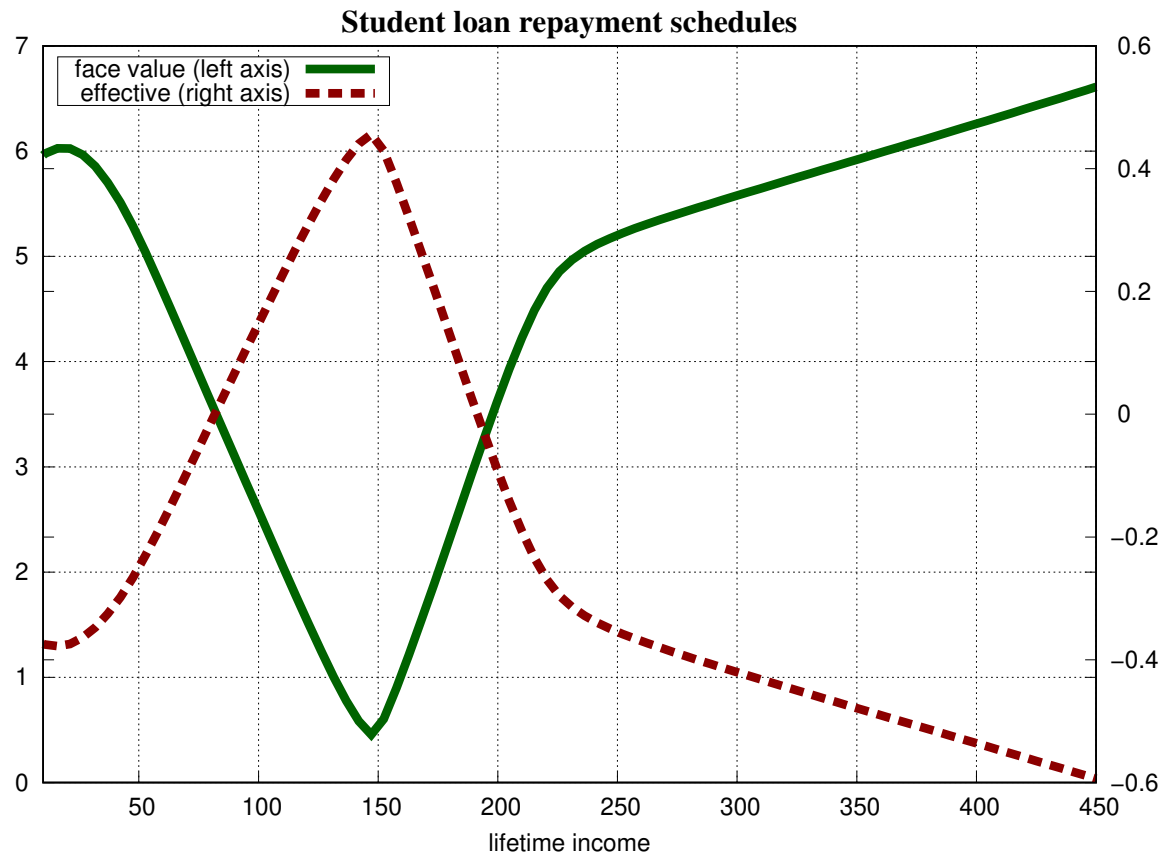

Figure 5: Optimal student loan repayment schedule $r(e, y)$

The effective student loan repayment schedule, which is determined by the difference between the repayment schedule and the tax deduction, is largely shaped by optimal the labor distortion as explained in the previous implementation. What is significant is that this decentralization uses student loan repayments as a retirement savings vehicle for collegeeducated agents. More specifically, our implementation constructs the social security benefits to match the optimal retirement consumption of high-school graduates. The student loan repayments at its face value are designed to supplement the social security benefits so collegeeducated agents consume the optimum during retirement.

At the heart of the implementation is the idea that while college graduates repay their student loans, at the same time they save for retirement. The contribution matching rate $\alpha$ that arises in our proposed implementation amounts to $1.84 \%$, which is close to the actual rate used by the IRS ruling from May $2018 .{ }^{8}$

${ }^{8}$ The IRS ruling number 201833012 approved a plan in which an employee's student loan repayment equivalent to at least $2 \%$ of his or her compensation would be matched with contributions to their retirement account equal to $5 \%$ of their eligible compensation. 


\section{Extensions}

\subsection{Heterogeneous Present Bias}

In this section, we extend our results to an environment with heterogeneous present bias. We assume that agents with innate ability $\gamma$ have present bias $\beta_{\gamma}$. Furthermore, we assume that $1 \geq \beta_{H}>\beta_{L}$. This assumption follows from the well-known marshmallow test. It also allows us to bypass the multi-dimensional screening problem which greatly simplifies the analysis. The following proposition characterizes the optimal wedges.

Proposition 5 The constrained efficient allocation with heterogeneous present bias satisfies

i. the inverse Euler equations (1), (2) and for any $\theta \in \Theta$,

$$
\begin{gathered}
\frac{1}{\beta_{H} u^{\prime}\left(c_{2}(H, \theta)\right)}=\frac{1}{u^{\prime}\left(c_{1}(H, \theta)\right)}+\left(\frac{1-\beta_{H}}{\beta_{H}}\right)\left(\frac{\pi_{H}+\beta_{H} \mu}{\pi_{H}+\mu}\right) \frac{1}{u^{\prime}\left(c_{0}(H)\right)}, \\
\frac{1}{\beta_{L} u^{\prime}\left(c_{2}(L, \theta)\right)}=\frac{1}{u^{\prime}\left(c_{1}(L, \theta)\right)}+\left(\frac{1-\beta_{L}}{\beta_{L}}\right)\left(\frac{\pi_{L}-\beta_{H} \mu\left(\frac{f\left(\theta \mid \kappa_{L, H}\right)}{f\left(\theta \mid \kappa_{L}\right)}\right)}{\pi_{L}-\mu}\right) \frac{1}{u^{\prime}\left(c_{0}(L)\right)},
\end{gathered}
$$

where $\mu=\left[u^{\prime}\left(c_{0}(L)\right)-u^{\prime}\left(c_{0}(H)\right)\right]\left[\frac{u^{\prime}\left(c_{0}(L)\right)}{\pi_{L}}+\frac{u^{\prime}\left(c_{0}(H)\right)}{\pi_{H}}\right]^{-1}$.

ii. the labor wedge for any $\gamma$ and $\theta$ satisfies ( 7 ) and

$$
\begin{aligned}
& \frac{\tau^{w}(L, \theta)}{1-\tau^{w}(L, \theta)}=A_{L}(\theta) B_{L}(\theta) \\
& \times\left[C_{L}(\theta)-\left(\frac{1-F\left(\theta \mid \kappa_{L, H}\right)}{1-F\left(\theta \mid \kappa_{L}\right)}\right) D_{L}(\theta)+\frac{\frac{\beta_{L}}{1-\beta_{L}} h\left(\theta \mid \kappa_{L}\right)}{\frac{\beta_{H}}{1-\beta_{H}} h\left(\theta \mid \kappa_{L, H}\right)} E_{L}(\theta)\right], \\
& \text { where } E_{\gamma}(\theta)=\left[\frac{u^{\prime}\left(c_{1}(\gamma, \theta)\right)}{\beta_{\gamma} u^{\prime}\left(c_{2}(\gamma, \theta)\right)}-1\right]-\left(\frac{1-\beta_{\gamma}}{\beta_{\gamma}}\right) \frac{u^{\prime}\left(c_{1}(\gamma, \theta)\right)}{\phi} \text { and } \frac{1}{\phi}=\mathbb{E}_{\gamma}\left[\mathbb{E}_{\theta}\left(\frac{1}{u^{\prime}\left(c_{1}(\gamma, \theta)\right)} \mid \gamma\right)\right] .
\end{aligned}
$$

Though the economic forces determining the wedges for $H$-agents remain unchanged, Proposition 5 does provide us with insights on how the optimal policy leverages the difference in $\beta$ in the $L$-agents' wedges. For the intertemporal wedge $\tau_{1}^{k}(L, \theta)$, recall that the optimal policy recommends front-loading consumption for high-income $L$-agents. Here, this frontloading is even more perverse. It takes advantage of the fact that $H$-agents are relatively more consistent, and an exacerbation of $\tau_{1}^{k}(L, \theta)$ further relaxes the ex-ante incentive constraints. A similar logic applies for the labor wedge $\tau^{w}(L, \theta)$, which also differs from the case with 
homogeneous $\beta$. Recall that the present-bias component $E_{L}(\theta)$ is enhanced in the labor distortions for $L$-agents to deter $H$-agents from mimicking. Here, the labor distortion for $L$-agents coming from the present-bias component is weakened. This is because $H$-agents are less tempted to mimic $L$-agents due to the larger intertemporal distortion, which relieves the labor distortions stemming from present bias.

A special case is when $H$-agents are time consistent while only $L$-agents are present biased $\left(\beta_{H}=1>\beta_{L}\right)$. From Proposition 5 , the $H$-agents' wedges share the same properties as the wedges for time-consistent agents. Also, the present-bias component $E_{L}(\theta)$ no longer influences the labor wedge of $L$-agents. Instead, the optimal policy takes advantage of present-biased $L$-agents entirely through the intertemporal distortion in retirement savings $\tau_{1}^{l}(L, \theta)$, which is worsened with time-consistent $H$-agents. Though linking student loan payments to retirement savings is not needed if college graduates are time consistent, education-dependent savings policies targeting non-college graduates is still optimal. We believe this case is a theoretical curiosity, since empirical studies have demonstrated pervasive present-biased behavior among college students (Ariely and Wertenbroch, 2002; Steel, 2007).

\subsection{Non-Sophisticated Agents}

The paper has focused on sophisticated present-biased agents. Sophisticated agents fully anticipate the behavior of their future-selves, so they have a demand for commitment. On the other hand, non-sophisticated agents underestimate the severity of their bias and tend to demand too little commitment. ${ }^{9}$ We explore the implications of non-sophistication on the design of optimal policy in this section.

To model non-sophistication, we follow O'Donoghue and Rabin (2001). Agents at $t=0$ perceive their present bias in $t=1$ to be $\hat{\beta} \in[\beta, 1]$. Let $W_{1}\left(c_{1}, c_{2}, y ; \gamma, \theta, e, \hat{\beta}\right)$ denote the non-sophisticated agents' perceived utility in $t=1: W_{1}\left(c_{1}, c_{2}, y ; \gamma, \theta, e, \hat{\beta}\right)=u\left(c_{1}\right)-h\left(\frac{y}{\theta}\right)+$ $\hat{\beta} \delta_{2} u\left(c_{2}\right)$, Clearly, if $\hat{\beta}=\beta$, the agent is sophisticated and fully aware of the bias. If $\hat{\beta}=1$, the agent is fully naïve and believe their future-self to be time-consistent. Partially naïve agents know they are present-biased, $\hat{\beta}<1$, but they underestimate its severity, $\hat{\beta}>\beta$. We assume agents have heterogeneous and unobservable sophistication distributed within support $[\underline{\hat{\beta}}, 1]$, where $\underline{\hat{\beta}} \in(\beta, 1]$.

$\mathrm{Yu}(2018 \mathrm{a})$ showed that it is optimal for the government to take advantage of the misspecified beliefs of present-biased agents through the preference arbitrage mechanism (PAM). PAM features off-path allocation used to exploit the incorrect beliefs, which are referred to as the imaginary allocations denoted as $\left(c^{I}, y^{I}\right)$. The allocation the government implements

\footnotetext{
${ }^{9}$ Recent studies suggest that individuals may not be sophisticated (Chan, 2017).
} 
on-path is called the real allocations denoted as $(c, y)$. We assume that $u$ is unbounded below and above $\left(u\left(\mathbb{R}_{+}\right)=\mathbb{R}\right)$. For $H$-agents, the government designs the menu

$$
\hat{P}_{H}=\left\{c_{0}(H),\left[c_{1}^{I}, y^{I}, c_{2}^{I}\right],\left[c_{1}(H, \theta), y(H, \theta), c_{2}(H, \theta)\right]_{\theta \in \Theta}\right\}
$$

At $t=1, H$-agents choose between imaginary and real allocations. The imaginary allocations are designed so that at $t=0$, the agents mistakenly believe their future-selves will choose the imaginary allocations, but they actually end-up selecting the real allocations instead. Since the ex-ante incentive constraints are non-binding for $L$-agents, the government does not need to design imaginary allocations for them, so $\hat{P}_{L}=\left\{c_{0}(L),\left[c_{1}(L, \theta), y(L, \theta), c_{2}(L, \theta)\right]_{\theta \in \Theta}\right\}$. Similar to $\mathrm{Yu}$ (2018a), it is not necessary to design imaginary allocations tailored for each level of sophistication. It is possible to find a single set of imaginary allocations such that it implements the same real allocations for agents of any sophistication.

Lemma 4 For non-sophisticated present-biased agents, the ex-ante incentive compatibility constraint is non-binding at the optimum.

To understand Lemma 4, note that non-sophisticated agents over-estimate the value of retirement consumption to their future-selves. PAM takes advantage of incorrect beliefs by loading the information rent on the imaginary retirement consumption $c_{2}^{I}$, which agents believe they will choose in $t=1$ but their future-selves forsake for more immediate gratification. The following proposition describes the optimal wedges for non-sophisticated agents.

Proposition 6 The constrained efficient allocation for non-sophisticated agents satisfies

i. full insurance in $t=0: c_{0}(H)=c_{0}(L)$,

ii. the inverse Euler equations: for any $\gamma$,

$$
\frac{1}{u^{\prime}\left(c_{0}(\gamma)\right)}=\mathbb{E}_{\theta}\left(\frac{1}{u^{\prime}\left(c_{1}(\gamma, \theta)\right)}\right)=\mathbb{E}_{\theta}\left(\frac{1}{u^{\prime}\left(c_{2}(\gamma, \theta)\right)}\right)
$$

and, for any $\theta$,

$$
\frac{1}{\beta u^{\prime}\left(c_{2}(\gamma, \theta)\right)}=\frac{1}{u^{\prime}\left(c_{1}(\gamma, \theta)\right)}+\left(\frac{1-\beta}{\beta}\right) \frac{1}{u^{\prime}\left(c_{0}(\gamma)\right)}
$$

iii. the labor wedge for any $\gamma$ and $\theta$ satisfies

$$
\frac{\tau^{w}(\gamma, \theta)}{1-\tau^{w}(\gamma, \theta)}=A_{\gamma}(\theta) B_{\gamma}(\theta) C_{\gamma}(\theta)
$$


Proposition 6 demonstrates the government's ability to fully insure agents against differences in innate ability $\gamma$. This is not surprising, because Lemma 4 stated that the government can screen innate ability without distortions by utilizing PAM. As a result, the only distortions in the economy stem from the unobserved productivity $\theta$ realized in $t=1$.

Since innate ability is screened for free but productivity is not, Proposition 6 shows that the intertemporal wedge $\tau_{0}^{k}(\gamma)$ is characterized by the standard inverse Euler equation for all innate ability types. This is because the government no longer needs the additional intertemporal distortions illustrated in Proposition 1 on $\tau_{0}^{k}(\gamma)$ to incentivize investment in human capital. The imaginary allocations are sufficient for that purpose. However, productivity remains unobservable by the government, so savings in $t=0$ is still restricted and shaped by the inverse Euler equation to relax the ex-post incentive constraints.

More interestingly, Proposition 6 shows that all agents are provided with a commitment device: for any $\gamma$ and $\theta, \frac{u^{\prime}\left(c_{1}(\gamma, \theta)\right)}{u^{\prime}\left(c_{2}(\gamma, \theta)\right)}>\beta$. With non-sophisticated agents, the government can focus on its paternalistic goals since it no longer needs to use commitment as information rent to screen innate ability. More specifically, notice for any $\gamma$, the expected intertemporal distortion is

$$
\mathbb{E}\left[\tau_{1}^{k}(\gamma, \theta)\right]=(1-\beta)\left[1-\frac{\mathbb{E}\left[u^{\prime}\left(c_{1}(\gamma, \theta)\right)\right]}{u^{\prime}\left(c_{0}(\gamma)\right)}\right] .
$$

Since the inverse Euler implies $u^{\prime}\left(c_{0}(\gamma)\right)<\mathbb{E}\left[u^{\prime}\left(c_{1}(\gamma, \theta)\right)\right]$, we have $\mathbb{E}\left[\tau_{1}^{k}(\gamma, \theta)\right]<0$. In essence, agents over-save for retirement in expectation. This is due to the disagreement between the paternalistic government and present-biased agents at $t=1$. The government uses this disagreement to deter downward deviations by back-loading the consumption of lower productivity types, while increasing output of more productive agents by rewarding them with a more front-loaded consumption path. Since it is less costly in terms of resources to decrease working-period consumption $c_{1}$ than to increase it, the consumption path is slightly back-loaded on average. Without this disagreement, it is most efficient to motivate agents to work by respecting their intertemporal preferences and screen through the standard downward labor distortion.

Finally, Proposition 6 shows that the optimal labor distortion is determined solely by the intratemporal component. This means the economic forces that shape the labor wedge are essentially static. Recall from Proposition 2 that both the intertemporal and presentbias components are integral to the optimal provision of dynamic incentives through labor distortion. Since the ex-ante incentive constraint is non-binding, the forces that determine the provision of dynamic incentives are absent from the labor wedge. As a result, the intertemporal and present-bias components no longer influence labor distortion. 


\section{Conclusion}

This paper formulates the optimal education and retirement policies in a dynamic Mirrlees model with present-biased agents. In this environment, the inverse Euler equation only holds in expectation, but the labor wedge is quantitatively similar to the case with timeconsistent agents. A novel contribution of this paper is to show that the optimal retirement savings policy should depend on education. More specifically, we show how linking student loan repayments to retirement savings along with some qualitative changes to existing policies can implement the optimum. We also estimate the welfare gains from these policies to be significant.

\section{References}

Anderberg, Dan, "Optimal Policy and the Risk Properties of Human Capital Reconsidered," Journal of Public Economics, 2009, 93, 1017-1026.

Angeletos, George-Marios, David Laibson, Andrea Repetto, Jeremy Tobacman, and Stephen Weinberg, "The Hyperbolic Consumption Model: Calibration, Simulation, and Empirical Evaluation," Journal of Economic Perspectives, 2001, 15 (3), 47-68.

Ariely, Dan and Klaus Wertenbroch, "Procrastination, Deadlines, and Performance: Self-Control by Precommitment," Psychological Science, 2002, 13 (3), 219-224.

Bohacek, Radim and Marek Kapicka, "Optimal Human Capital Policies," Journal of Monetary Economics, 2008, 55, 1-16.

Bovenberg, A. Lans and Bas Jacobs, "Redistribution and Education Subsidies are Siamese Twins," Journal of Public Economics, 2005, 89, 2005-2035.

Cadena, Brian and Benjamin Keys, "Human Capital and the Lifetime Costs of Impatience," American Economic Journal: Economic Policy, 2015, 7 (3), 126-153.

Carneiro, Pedro Manuel and James Heckman, "Human Capital Policy," IZA Discussion Paper No. 821, 2003.

Chan, Marc, "Welfare Dependence and Self-Control: An Empirical Analysis," Review of Economic Studies, 2017, 84, 1379-1423.

College Board, "Trends in College Pricing," NY: College Board Publications, 2018.

Craig, Ashley, "Optimal Income Taxation with Spillovers from Employer Learning," Working Paper, 2019.

Cunha, Flavio and James Heckman, "Identifying and Estimating the Distributions of Ex Post and Ex Ante Returns to Schooling," Labour Economics, 2007, 14 (6), 870-893.

Diamond, Peter, "Optimal Income Taxation: An Example with a U-Shaped Pattern of Optimal Marginal Tax Rates," American Economic Review, 1998, 96 (3), 694-719. 
Farhi, Emmanuel and Xavier Gabaix, "Optimal Taxation with Behavioral Agents," Working Paper, 2017.

Findeisen, Sebastian and Dominik Sachs, "Education and Optimal Dynamic Taxation: The Role of Income-Contingent Student Loans," Journal of Public Economics, 2016, 138, $1-21$.

Gabaix, Xavier, "A Sparsity-Based Model of Bounded Rationality," Quarterly Journal of Economics, 2014, 129 (4), 1661-1710.

Galperti, Simone, "Commitment, Flexibility, and Optimal Screening of Time Inconsistency," Econometrica, 2015, 83 (4), 1425-1465.

Gary-Bobo, Robert and Alain Trannoy, "Optimal Student Loans and Graduate Tax under Moral Hazard and Adverse Selection," The RAND Journal of Economics, 2015, 46 (3), 546576 .

Golosov, Mikhail, Maxim Troshkin, and Aleh Tsyvinski, "Redistribution and Social Insurance," American Economic Review, 2016, 106 (2), 359-386.

_ , Narayana Kocherlakota, and Aleh Tsyvinski, "Optimal Indirect and Capital Taxation," Review of Economic Studies, 2003, 70 (3), 569-587.

Grochulski, Borys and Tomasz Piskorski, "Risky Human Capital and Deferred Capital Income Taxation," Journal of Economic Theory, 2010, 145, 908-943.

Halac, Marina and Pierre Yared, "Fiscal Rules and Discretion Under Persistent Shocks," Econometrica, 2014, 82 (5), 1557-1614.

Heathcote, Jonathan and Hitoshi Tsujiyama, "Optimal Income Taxation: Mirrlees Meets Ramsey," Working Paper, 2017.

_, Kjetil Storesletten, and Giovanni Violante, "Optimal Tax Progressivity: An Analytical Framework," Quarterly Journal of Economics, 2017, 132 (4), 1693-1754.

Kapicka, Marek, "Optimal Mirrleesean Taxation in a Ben-Porath Economy," American Economic Journal: Macroeconomics, 2015, 7 (2), 219-248.

- and Julian Neira, "Optimal Taxation with Risky Human Capital," Working Paper, 2015.

Laibson, David, "Golden Eggs and Hyperbolic Discounting," Quarterly Journal of Economics, 1997, 112 (2), 443-477.

_, Peter Maxted, Andrea Repetto, and Jeremy Tobacman, "Estimating Discount Functions with Consumption Choices over the Lifecycle," Working Paper, 2017.

Lochner, Lance and Alexander Monge-Naranjo, "Student Loans and Repayment: Theory, Evidence and Policy," Working Paper, 2015.

Lockwood, Benjamin, "Optimal Income Taxation with Present Bias," Working Paper, 2016.

Makris, Miltiadis and Alessandro Pavan, "Taxation Under Learning-by-Doing," Work- 
ing Paper, 2018.

Meara, Ellen, Seth Richards, and David Cutler, "The Gap Gets Bigger: Changes in Mortality and Life expectancy by Education, 1981-2000," Health Affairs, 2008, 27 (2), 350-360.

Moser, Christian and Pedro Olea de Souza e Silva, "Paternalism vs Redistribution: Designing Retirement Savings Policies with Behavioral Agents," Working Paper, 2017.

Munnell, Alicia, Wenliang Hou, and Anthony Webb, "Will the Explosion of Student Debt Widen the Retirement Security Gap," Center for Retirement Research at Boston College, Issue in Brief, 2016, 16-2.

Nakajima, Makoto, "Rising indebtedness and temptation: A welfare analysis," Quantitative Economics, 2012, 3, 257-288.

Nigai, Sergey, "A Tale of Two Tails: Productivity Distribution and the Gains from Trade," Journal of International Economics, 2017, 104, 44-62.

O'Donoghue, Ted and Matthew Rabin, "Choice and Procrastination," Quarterly Journal of Economics, 2001, 116, 121-160.

Rutledge, Matthew, Geoffrey Sanzenbacher, and Francis Vitagliano, "How Does Student Debt Affect Early-Career Retirement Saving?," Center for Retirement Research Working Paper 2016-9, 2018.

Saez, Emmanuel, "Using Elasticities to Derive Optimal Income Tax Rates," Review of Economic Studies, 2001, 68, 205-229.

Stantcheva, Stefanie, "Optimal Taxation and Human Capital Policies over the Life Cycle," Journal of Political Economy, 2017, 125 (6), 1931-1990.

Steel, Piers, "The Nature of Procrastination: A Meta-Analytic and Theoretical Review of Quintessential Self-Regulatory Failure," Psychological Bulletin, 2007, 133 (1), 65-94.

Werning, Ivan, "Nonlinear Capital Taxation," Working Paper, 2011.

Yu, Pei Cheng, "Optimal Retirement Policies with Time-Inconsistent Agents," Working Paper, 2018.

_, "Seemingly Exploitative Contracts," Working Paper, 2018. 


\section{Appendices (for online publication)}

\section{A Derivation of the Theoretical Results}

Given Lemma 1, the relaxed optimal tax problem is

$$
\max _{P} \sum_{\gamma} \pi_{\gamma}\left[\delta_{0}\left(e_{\gamma}\right) u\left(c_{0}(\gamma)\right)+\delta_{1}\left(e_{\gamma}\right) \int_{\underline{\theta}}^{\bar{\theta}}\left[U_{1}(\gamma, \theta)+(1-\beta) \delta_{2} u\left(c_{2}(\gamma, \theta)\right)\right] f\left(\theta \mid \kappa_{\gamma}\right) d \theta\right]
$$

subject to

$$
\begin{gathered}
U_{1}(\gamma, \theta)=u\left(c_{1}(\gamma, \theta)\right)-h\left(\frac{y(\gamma, \theta)}{\theta}\right)+\beta \delta_{2} u\left(c_{2}(\gamma, \theta)\right) \\
\frac{\partial U_{1}(\gamma, \theta)}{\partial \theta}=\frac{y(\gamma, \theta)}{\theta^{2}} h^{\prime}\left(\frac{y(\gamma, \theta)}{\theta}\right) \\
\delta_{0}\left(e_{H}\right) u\left(c_{0}(H)\right)+\beta \delta_{1}\left(e_{H}\right) \int_{\underline{\theta}}^{\bar{\theta}}\left[U_{1}(H, \theta)+(1-\beta) \delta_{2} u\left(c_{2}(H, \theta)\right)\right] f\left(\theta \mid \kappa_{H}\right) d \theta \\
\geq \delta_{0}\left(e_{L}\right) u\left(c_{0}(L)\right)+\beta \delta_{1}\left(e_{L}\right) \int_{\underline{\theta}}^{\bar{\theta}}\left[U_{1}(L, \theta)+(1-\beta) \delta_{2} u\left(c_{2}(L, \theta)\right)\right] f\left(\theta \mid \kappa_{L, H}\right) d \theta,
\end{gathered}
$$

and the resource constraint. As is standard, we ignore the monotonicity constraint, $y(\gamma, \theta)$ is non-decreasing in $\theta$, and check it later. Also, we assume that the ex-ante incentive constraint for $H$-agents binds and show that the incentive constraint for $L$-agents hold when $\mid F\left(\theta \mid \kappa_{H}\right)-$ $F\left(\theta \mid \kappa_{H, L}\right)|-| F\left(\theta \mid \kappa_{L, H}\right)-F\left(\theta \mid \kappa_{L}\right) \mid$ is sufficiently large and positive (Lemma 2).

Let $\left(\lambda_{\gamma}(\theta), \xi_{\gamma}(\theta), \mu, \phi\right)$ be the multipliers on (9), (10), ex-ante incentive compatibility and resource constraint respectively. Using standard Hamiltonian techniques, we derive the following necessary conditions for optimality

$$
\begin{gathered}
\left(1+\frac{\mu}{\pi_{H}}\right) u^{\prime}\left(c_{0}(H)\right)=\left(1-\frac{\mu}{\pi_{L}}\right) u^{\prime}\left(c_{0}(L)\right)=\phi \\
\left(\pi_{H}+\beta \mu\right) \delta_{1}\left(e_{H}\right) f\left(\theta \mid \kappa_{H}\right)-\xi_{H}^{\prime}(\theta)=\lambda_{H}(\theta) \\
{\left[\pi_{L}-\beta \mu\left(\frac{f\left(\theta \mid \kappa_{L, H}\right)}{f\left(\theta \mid \kappa_{L}\right)}\right)\right] \delta_{1}\left(e_{L}\right) f\left(\theta \mid \kappa_{L}\right)-\xi_{L}^{\prime}(\theta)=\lambda_{L}(\theta),} \\
(1-\beta)\left(\pi_{H}+\beta \mu\right) \delta_{1}\left(e_{H}\right) f\left(\theta \mid \kappa_{H}\right)+\beta \lambda_{H}(\theta)=\frac{\phi \pi_{H} \delta_{1}\left(e_{H}\right) f\left(\theta \mid \kappa_{H}\right)}{u^{\prime}\left(c_{2}(H, \theta)\right)} \\
(1-\beta)\left[\pi_{L}-\beta \mu\left(\frac{f\left(\theta \mid \kappa_{L, H}\right)}{f\left(\theta \mid \kappa_{L}\right)}\right)\right] \delta_{1}\left(e_{L}\right) f\left(\theta \mid \kappa_{L}\right)+\beta \lambda_{L}(\theta)=\frac{\phi \pi_{L} \delta_{1}\left(e_{L}\right) f\left(\theta \mid \kappa_{L}\right)}{u^{\prime}\left(c_{2}(L, \theta)\right)},
\end{gathered}
$$


and for all $\gamma$,

$$
\begin{gathered}
\lambda_{\gamma}(\theta) u^{\prime}\left(c_{1}(\gamma, \theta)\right)=\phi \pi_{\gamma} \delta_{1}\left(e_{\gamma}\right) f\left(\theta \mid \kappa_{\gamma}\right), \\
\xi_{\gamma}(\underline{\theta})=\xi_{\gamma}(\bar{\theta})=0, \\
\lambda_{\gamma}(\theta) \frac{1}{\theta} h^{\prime}\left(\frac{y(\gamma, \theta)}{\theta}\right)+\xi_{\gamma}(\theta)\left[\frac{1}{\theta^{2}} h^{\prime}\left(\frac{y(\gamma, \theta)}{\theta}\right)+\frac{y(\gamma, \theta)}{\theta^{3}} h^{\prime \prime}\left(\frac{y(\gamma, \theta)}{\theta}\right)\right] \\
=\phi \pi_{\gamma} \delta_{1}\left(e_{\gamma}\right) f\left(\theta \mid \kappa_{\gamma}\right) .
\end{gathered}
$$

Below, we show that the theoretical results follow from these conditions.

Proof of Lemma 2: The ex-ante utility can be expressed as

$$
U_{0}\left(\gamma^{\prime} ; \gamma\right)=\delta_{0}\left(e_{\gamma^{\prime}}\right) u\left(c_{0}\left(\gamma^{\prime}\right)\right)+\beta \delta_{1}\left(e_{\gamma^{\prime}}\right) \int_{\underline{\theta}}^{\bar{\theta}}\left[U_{1}\left(\gamma^{\prime}, \theta\right)+(1-\beta) \delta_{2} u\left(c_{2}\left(\gamma^{\prime}, \theta\right)\right)\right] f\left(\theta \mid \kappa_{\gamma^{\prime}, \gamma}\right) d \theta
$$

Suppose the downward ex-ante incentive constraint binds: $U_{0}(H)=U_{0}(L ; H)$. Then, combining both ex-ante incentive constraints yields

$$
\begin{aligned}
\delta_{1}\left(e_{H}\right) \int_{\underline{\theta}}^{\bar{\theta}}\left[U_{1}(H, \theta)+(1-\beta) \delta_{2} u\left(c_{2}(H, \theta)\right)\right]\left[f\left(\theta \mid \kappa_{H}\right)-f\left(\theta \mid \kappa_{H, L}\right)\right] d \theta \\
\quad \geq \delta_{1}\left(e_{L}\right) \int_{\underline{\theta}}^{\bar{\theta}}\left[U_{1}(L, \theta)+(1-\beta) \delta_{2} u\left(c_{2}(L, \theta)\right)\right]\left[f\left(\theta \mid \kappa_{L, H}\right)-f\left(\theta \mid \kappa_{L}\right)\right] d \theta .
\end{aligned}
$$

Through integration by parts, the inequality above can be rewritten as

$$
\begin{aligned}
& \delta_{1}\left(e_{L}\right) \int_{\underline{\theta}}^{\bar{\theta}}\left[\frac{\partial U_{1}(L, \theta)}{\partial \theta}+(1-\beta) \delta_{2} \frac{\partial u\left(c_{2}(L, \theta)\right)}{\partial \theta}\right]\left[F\left(\theta \mid \kappa_{L, H}\right)-F\left(\theta \mid \kappa_{L}\right)\right] d \theta \\
& \geq \delta_{1}\left(e_{H}\right) \int_{\underline{\theta}}^{\bar{\theta}}\left[\frac{\partial U_{1}(H, \theta)}{\partial \theta}+(1-\beta) \delta_{2} \frac{\partial u\left(c_{2}(H, \theta)\right)}{\partial \theta}\right]\left[F\left(\theta \mid \kappa_{H}\right)-F\left(\theta \mid \kappa_{H, L}\right)\right] d \theta .
\end{aligned}
$$

Since the allocation satisfies ex-post incentive compatibility, by Lemma $1, U_{1}(\gamma, \theta)$ and $y(\gamma, \theta)$ are non-decreasing in $\theta$. This implies that $u\left(c_{1}(\gamma, \theta)\right)+\beta \delta_{2} u\left(c_{2}(\gamma, \theta)\right)$ is non-decreasing in $\theta$. At the optimum when $U_{0}(H)=U_{0}(L ; H)$, the first order conditions hold, which shows that $u\left(c_{2}(H, \theta)\right)$ is non-decreasing in $\theta$. Also, since $F\left(\theta \mid \kappa_{H}\right) \leq F\left(\theta \mid \kappa_{H, L}\right)$ for all $\theta$, the right hand side of inequality (11) is negative. Hence, if $\left|F\left(\theta \mid \kappa_{H}\right)-F\left(\theta \mid \kappa_{H, L}\right)\right|-\left|F\left(\theta \mid \kappa_{L, H}\right)-F\left(\theta \mid \kappa_{L}\right)\right|$ is large, then $U(L) \geq U(H ; L)$. 
Proof of Proposition 1: Conditions (3) and (4) and $\mu$ follow from the first order conditions. The inverse Euler equations (1) and (2) are derived using the perturbation argument.

Let $P=\left\{c_{0}(\gamma),\left[c_{t}(\gamma, \theta), y(\gamma, \theta)\right]_{t>0, \theta \in \Theta}\right\}_{\gamma}$ be the allocation that solves the constrained efficient planning problem. We first derive (2) by considering a small increase in $c_{2}(\gamma, \theta)$ across $\theta$ for a fixed $\gamma$. That is define $u\left(\tilde{c}_{2}(\gamma, \theta)\right)=u\left(c_{2}(\gamma, \theta)\right)+\Delta$ for some small $\Delta$. We simultaneously decrease $c_{1}(\gamma, \theta)$ for all $\theta$ such that $u\left(\tilde{c}_{1}(\gamma, \theta)\right)=u\left(c_{1}(\gamma, \theta)\right)-\delta_{2} \Delta$. Such perturbations do not affect the objective function, the ex-ante incentive compatibility and the ex-post incentive compatibility. It only affects the resource constraint. Note that the perturbation must be the same for all $\theta$ or else it may violate ex-post incentive compatibility, which is not the case if $\beta=1$. If $P$ is optimal, then it must be that $\Delta=0$ minimizes the resource used, i.e.,

$$
0=\arg \min _{\Delta} \int_{\Theta}\left[-u^{-1}\left[u\left(c_{1}(\gamma, \theta)\right)-\delta_{2} \Delta\right]-\frac{1}{R_{2}} u^{-1}\left[u\left(c_{2}(\gamma, \theta)\right)+\Delta\right]\right] f\left(\theta \mid \kappa_{\gamma}\right) d \theta .
$$

Evaluating the first order condition of this problem at $\Delta=0$ yields (2).

Similarly, to derive (1), we consider a small decrease in $c_{1}(\gamma, \theta)$ across $\theta$ for all $\gamma$ such that $u\left(\tilde{c}_{1}(\gamma, \theta)\right)=u\left(c_{1}(\gamma, \theta)\right)-\frac{1}{\delta_{1}\left(e_{\gamma}\right)} \Delta$ for some small $\Delta$. We simultaneously increase $c_{0}(\gamma)$ for all $\gamma$ such that $u\left(\tilde{c}_{0}(\gamma)\right)=u\left(c_{0}(\gamma)\right)+\frac{1}{\delta_{0}\left(e_{\gamma}\right)} \Delta$. Since it is perturbed for all $\theta$, the ex-post incentive compatibility constraint is not affected. Also, notice that the ex-ante incentive compatibility constraint and objective function are not affected, but the resource constraint changes. Crucially, the perturbation must be the same for all $\gamma$ or it may violate ex-ante incentive compatibility, which is not the case if $\beta=1$. If $P$ is optimal, then $\Delta=0$ solves,

$$
\min _{\Delta} \sum_{\gamma} \pi_{\gamma}\left\{\frac{-u^{-1}\left[u\left(c_{0}(\gamma)\right)+\frac{\Delta}{\delta_{0}\left(e_{\gamma}\right)}\right]}{R_{0}\left(e_{\gamma}\right)}-\frac{1}{R_{1}\left(e_{\gamma}\right)} \int_{\Theta} u^{-1}\left[u\left(c_{1}(\gamma, \theta)\right)-\frac{\Delta}{\delta_{1}\left(e_{\gamma}\right)}\right] f\left(\theta \mid \kappa_{\gamma}\right) d \theta\right\}
$$

Evaluating the first order condition of this problem at $\Delta=0$ yields (1).

Proof of Proposition 2: From the first order conditions, we have

$$
\begin{gathered}
\xi_{H}(\theta)=\int_{\theta}^{\bar{\theta}}\left[\lambda_{H}(x)-\left(\pi_{H}+\beta \mu\right) \delta_{1}\left(e_{H}\right) f\left(x \mid \kappa_{H}\right)\right] d x, \\
\xi_{L}(\theta)=\int_{\theta}^{\bar{\theta}}\left[\lambda_{L}(x)-\left[\pi_{L} f\left(x \mid \kappa_{L}\right)-\beta \mu f\left(x \mid \kappa_{L, H}\right)\right] \delta_{1}\left(e_{L}\right)\right] d x .
\end{gathered}
$$

First, we derive (7). Since $\lambda_{\gamma}(\theta)=\frac{\phi \pi_{\gamma} \delta_{1}\left(e_{\gamma}\right) f\left(\theta \mid \kappa_{\gamma}\right)}{u^{\prime}\left(c_{1}(\gamma, \theta)\right)}$, we rewrite the first order condition on 
$y(H, \theta)$ as

$$
\begin{aligned}
& \phi \pi_{H} \delta_{1}\left(e_{H}\right) f\left(\theta \mid \kappa_{H}\right)\left[1-\frac{\frac{1}{\theta} h^{\prime}\left(\frac{y(H, \theta)}{\theta}\right)}{u^{\prime}\left(c_{1}(H, \theta)\right)}\right] \\
= & {\left[\frac{1}{\theta^{2}} h^{\prime}\left(\frac{y(H, \theta)}{\theta}\right)+\frac{y(H, \theta)}{\theta^{3}} h^{\prime \prime}\left(\frac{y(H, \theta)}{\theta}\right)\right] \int_{\theta}^{\bar{\theta}}\left[\lambda_{H}(x)-\left(\pi_{H}+\beta \mu\right) \delta_{1}\left(e_{H}\right) f\left(x \mid \kappa_{H}\right)\right] d x . }
\end{aligned}
$$

Let $A_{\gamma}(\theta)=\frac{1-F\left(\theta \mid \kappa_{\gamma}\right)}{\theta f\left(\theta \mid \kappa_{\gamma}\right)}$ and $B_{\gamma}(\theta)=1+\frac{\frac{y(\gamma, \theta)}{\theta} h^{\prime \prime}\left(\frac{y(\gamma, \theta)}{\theta}\right)}{h^{\prime}\left(\frac{y(\gamma, \theta)}{\theta}\right)}$, then dividing both sides by $\frac{1}{\theta} h^{\prime}\left(\frac{y(H, \theta)}{\theta}\right) \phi \pi_{H} \delta_{1}\left(e_{H}\right) f\left(\theta \mid \kappa_{H}\right)$ yields

$$
\begin{aligned}
& \frac{1}{\frac{1}{\theta} h^{\prime}\left(\frac{y(H, \theta)}{\theta}\right)}-\frac{1}{u^{\prime}\left(c_{1}(H, \theta)\right)} \\
& \quad=A_{H}(\theta) B_{H}(\theta) \int_{\theta}^{\bar{\theta}}\left[\frac{\lambda_{H}(x)}{\phi \pi_{H} \delta_{1}\left(e_{H}\right) f\left(x \mid \kappa_{H}\right)}-\frac{\pi_{H}+\beta \mu}{\phi \pi_{H}}\right] \frac{f\left(x \mid \kappa_{H}\right)}{1-F\left(\theta \mid \kappa_{H}\right)} d x .
\end{aligned}
$$

By definition $\frac{1}{\theta} h^{\prime}\left(\frac{y(\gamma, \theta)}{\theta}\right)=\left(1-\tau^{w}(\gamma, \theta)\right) u^{\prime}\left(c_{1}(\gamma, \theta)\right)$ and from the first order condition $\frac{\lambda_{\gamma}(x)}{\phi \pi_{\gamma} \delta_{1}\left(e_{\gamma}\right) f\left(x \mid \kappa_{\gamma}\right)}=\frac{1}{u^{\prime}\left(c_{1}(\gamma, x)\right)}$, so we have

$$
\begin{aligned}
& \frac{1}{u^{\prime}\left(c_{1}(H, \theta)\right)}\left(\frac{\tau^{w}(H, \theta)}{1-\tau^{w}(H, \theta)}\right)= \\
& A_{H}(\theta) B_{H}(\theta)\left[\int_{\theta}^{\bar{\theta}} \frac{1}{u^{\prime}\left(c_{1}(H, x)\right)} \frac{f\left(x \mid \kappa_{H}\right)}{1-F\left(\theta \mid \kappa_{H}\right)} d x-\frac{\pi_{H}+\beta \mu}{\phi \pi_{H}}\right] .
\end{aligned}
$$

Observe $\frac{\beta \mu}{\phi \pi_{H}}=\frac{\mu}{\phi \pi_{H}}-\frac{(1-\beta) \mu}{\phi \pi_{H}}$, then by the first order conditions, we can substitute in $\frac{\mu}{\phi \pi_{H}}=\frac{1}{u^{\prime}\left(c_{0}(H)\right)}-\frac{1}{\phi}$ and $\frac{(1-\beta) \mu}{\phi \pi_{H}}=\frac{1}{\beta u^{\prime}\left(c_{2}(H, \theta)\right)}-\frac{1}{u^{\prime}\left(c_{1}(H, \theta)\right)}-\left(\frac{1-\beta}{\beta}\right) \frac{1}{\phi}$. Define $C_{\gamma}(\theta)=\int_{\theta}^{\bar{\theta}} \frac{u^{\prime}\left(c_{1}(\gamma, \theta)\right)}{u^{\prime}\left(c_{1}(\gamma, x)\right)}\left[1-\frac{u^{\prime}\left(c_{1}(\gamma, x)\right)}{\phi}\right] \frac{f\left(x \mid \kappa_{\gamma}\right)}{1-F\left(\theta \mid \kappa_{\gamma}\right)} d x, D_{\gamma}(\theta)=u^{\prime}\left(c_{1}(\gamma, \theta)\right)\left[\frac{1}{u^{\prime}\left(c_{0}(\gamma)\right)}-\frac{1}{\phi}\right]$, $E_{\gamma}(\theta)=\left[\frac{u^{\prime}\left(c_{1}(\gamma, \theta)\right)}{\beta u^{\prime}\left(c_{2}(\gamma, \theta)\right)}-1\right]-\left(\frac{1-\beta}{\beta}\right) \frac{u^{\prime}\left(c_{1}(\gamma, \theta)\right)}{\phi}$ and multiplying both sides by $u^{\prime}\left(c_{1}(H, \theta)\right)$ yields the expression (7).

Using a similar process as above, we have the following expression for $\gamma=L$

$$
\frac{\tau^{w}(L, \theta)}{1-\tau^{w}(L, \theta)}=A_{L}(\theta) B_{L}(\theta)\left[C_{L}(\theta)-\int_{\theta}^{\bar{\theta}}\left(\frac{\pi_{L} f\left(x \mid \kappa_{L}\right)-\beta \mu f\left(x \mid \kappa_{L, H}\right)}{\phi \pi_{L}}\right) \frac{u^{\prime}\left(c_{1}(L, \theta)\right)}{1-F\left(\theta \mid \kappa_{L}\right)} d x\right]
$$

and integrating gives us (8). Furthermore, from the first order condition for $c_{0}$, we have $\phi=\left[\frac{\pi_{H}}{u^{\prime}\left(c_{0}(H)\right)}+\frac{\pi_{L}}{u^{\prime}\left(c_{0}(L)\right)}\right]^{-1}$, and (1) yields the expression. 
Proof of Lemma 3: For a fixed $\gamma$, suppose there exists $\tilde{\theta}$ and $\hat{\theta}$ such that $y(\gamma, \tilde{\theta})=y(\gamma, \hat{\theta})$. Let $\Phi(\gamma, \theta)=u\left(c_{1}(\gamma, \theta)\right)+\beta \delta_{2} u\left(c_{2}(\gamma, \theta)\right)$. There are two cases to consider. First, suppose $\Phi(\gamma, \tilde{\theta}) \neq \Phi(\gamma, \hat{\theta})$, then clearly the allocations are not incentive compatible. Next, suppose $\Phi(\gamma, \tilde{\theta})=\Phi(\gamma, \hat{\theta})$, and without loss of generality $c_{1}(\gamma, \tilde{\theta})>c_{1}(\gamma, \hat{\theta})$ and $c_{2}(\gamma, \tilde{\theta})<c_{2}(\gamma, \hat{\theta})$. Let $\tilde{\pi}$ and $\hat{\pi}$ denote the measure of $(\gamma, \tilde{\theta})$ and $(\gamma, \hat{\theta})$ agents. Let $\bar{u}_{t}=\frac{1}{\tilde{\pi}+\hat{\pi}}\left[\tilde{\pi} u\left(c_{t}(\gamma, \tilde{\theta})\right)+\hat{\pi} u\left(c_{t}(\gamma, \hat{\theta})\right)\right]$. By assigning these agents the average utility, the total welfare is unchanged and incentive compatibility is preserved. However, since $u$ is strictly concave, the consumption level that gives $\bar{u}_{1}$ and $\bar{u}_{2}$ relaxes the resource constraint. This means that it is not optimal for $c_{1}(\gamma, \tilde{\theta})>c_{1}(\gamma, \hat{\theta})$ and $c_{2}(\gamma, \tilde{\theta})<c_{2}(\gamma, \hat{\theta})$ with $\Phi(\gamma, \tilde{\theta})=\Phi(\gamma, \hat{\theta})$. In other words, the consumption paths are equivalent for agents of the same level of income.

Proof of Proposition 3: First, following Werning (2011), we construct bond savings tax $T^{k}(b)$ such that agents never purchase bonds. To see how, consider the government assigning the optimal allocation from the direct revelation mechanism given past and current reports, while agents are allowed to purchase any desired amount of bonds. Let $r=\left(r_{\gamma}, r_{\theta}\right)$ and define for each productivity realization $\theta$, current bond level $b_{1}$, past report $r_{\gamma}$, current report $r_{\theta}$, and bond savings $b_{2}$ a fictitious tax $T_{1}^{k}\left(b_{2}, r, \theta\right)$ paid in $t=1$ which makes the agent just indifferent between purchasing $b_{2}$ and reporting truthfully while not purchasing bonds in $t=1$ :

$$
\begin{aligned}
u\left(c_{1}(r)+R_{1}\left(e\left(r_{\gamma}\right)\right) b_{1}-b_{2}-T_{1}^{k}\left(b_{2}, r, \theta\right)\right) & -h\left(\frac{y(r)}{\theta}\right)+\beta \delta_{2} u\left(c_{2}(r)+R_{2} b_{2}\right) \\
& =u\left(c_{1}(\gamma, \theta)\right)-h\left(\frac{y(\gamma, \theta)}{\theta}\right)+\beta \delta_{2} u\left(c_{2}(\gamma, \theta)\right) .
\end{aligned}
$$

By setting the $\operatorname{tax} T_{1}^{k}\left(b_{2}, r, \theta\right)$ this way, the government can prevent agents from saving and misreporting. Next, by taking the supremum over all $\theta \in \Theta$, we obtain a bond savings tax $T_{1}^{k}\left(b_{2}, r\right)=\sup _{\theta \in \Theta} T_{1}^{k}\left(b_{2}, r, \theta\right)$ that is independent of productivity. Before we derive the bond savings tax in $t=0$, let

$$
\begin{aligned}
V\left(b_{1}, r_{\gamma}, \theta\right)=u\left(c_{1}\left(r_{\gamma}, \hat{r}_{\theta}\right)+R_{1}\left(e\left(r_{\gamma}\right)\right) b_{1}-\hat{b}_{2}-T_{1}^{k}\left(\hat{b}_{2}, r_{\gamma}, \hat{r}_{\theta}\right)\right) & \\
& -h\left(\frac{y\left(r_{\gamma}, \hat{r}_{\theta}\right)}{\theta}\right)+\delta_{2} u\left(c_{2}\left(r_{\gamma}, \hat{r}_{\theta}\right)+R_{2} \hat{b}_{2}\right),
\end{aligned}
$$


where

$$
\begin{array}{r}
\left(\hat{r}_{\theta}, \hat{b}_{2}\right) \in \arg \max _{r_{\theta}, b_{2}}\left\{u\left(c_{1}(r)+R_{1}\left(e\left(r_{\gamma}\right)\right) b_{1}-b_{2}-T_{1}^{k}\left(b_{2}, r\right)\right)\right. \\
\left.-h\left(\frac{y(r)}{\theta}\right)+\beta \delta_{2} u\left(c_{2}(r)+R_{2} b_{2}\right)\right\} .
\end{array}
$$

Next, define $T_{0}^{k}\left(b_{1}, r_{\gamma}\right)=\sup _{\gamma \in\{H, L\}} T_{0}^{k}\left(b_{1}, r_{\gamma}, \gamma\right)$ with $T_{0}^{k}\left(b_{1}, r_{\gamma}, \gamma\right)$ chosen such that

$$
\begin{array}{r}
\delta_{0}\left(e_{\gamma}\right) u\left(c_{0}\left(r_{\gamma}\right)-b_{1}-T_{0}^{k}\left(b_{2}, r_{\gamma}, \gamma\right)\right)+\beta \delta_{1}\left(e\left(r_{\gamma}\right)\right) \mathbb{E}\left[V\left(b_{1}, r_{\gamma}, \theta\right) \mid \gamma\right]=\delta_{0}\left(e_{\gamma}\right) u\left(c_{0}(\gamma)\right) \\
+\beta \delta_{1}\left(e_{\gamma}\right) \int_{\underline{\theta}}^{\bar{\theta}}\left[u\left(c_{1}(\gamma, \theta)\right)-h\left(\frac{y(\gamma, \theta)}{\theta}\right)+\delta_{2} u\left(c_{2}(\gamma, \theta)\right)\right] d F\left(\theta \mid \kappa\left(e_{\gamma}, \gamma\right)\right) .
\end{array}
$$

This yields tax functions $T_{0}^{k}\left(b_{1}, r_{\gamma}\right)$ and $T_{1}^{k}\left(b_{2}, r\right)$ which implement zero bond purchases in each period for any reports. Finally, by taking the supremum over all reports, we obtain a bond savings tax $T^{k}(b)=\sup _{r^{t}} T_{t}^{k}\left(b, r^{t}\right)$, where $r^{1}=r$ and $r^{0}=r_{\gamma}$, that only depends on bond purchases. With $T^{k}(b)$, agents do not purchase bonds in equilibrium.

Next, we construct the other policy instruments. By Lemma 3, we can define the optimal consumption derived from the direct mechanism as $\left(c_{0}(e), c_{1}(e, y), c_{2}(e, y)\right)$. First, we construct the student loans and its income-contingent repayment schedule along with the income tax. Let the loan amount be defined as

$$
L(e)=\left\{\begin{array}{ll}
c_{0}(e)+e & \text { if } e \in\left\{e_{L}, e_{H}\right\} \\
0 & \text { otherwise }
\end{array},\right.
$$

and the income-contingent repayment subsidy is $\tau^{e}\left(e_{L}, y\right)=1$ and

$$
\begin{aligned}
\tau^{e}\left(e_{H}, y\right)=1+\frac{1}{R_{1}\left(e_{H}\right) L\left(e_{H}\right)}\left[c_{1}\left(e_{H}, y\right)\right. & -c_{1}\left(e_{L}, y\right) \\
& \left.+\frac{c_{2}\left(e_{H}, y\right)}{R_{2}\left(1+\tau^{s}\left(e_{H}, y\right)\right)}-\frac{c_{2}\left(e_{L}, y\right)}{R_{2}\left(1+\tau^{s}\left(e_{L}, y\right)\right)}\right] .
\end{aligned}
$$

Let $y(\gamma, \theta)$ be the optimal output of type $(\gamma, \theta)$ agents in a direct revelation mechanism and define $Y=\{y \mid y=y(\gamma, \theta)$ with $\gamma \in\{L, H\}$ and $\theta \in \Theta\}$ to be the admissible set of income. The income tax is

$$
T(y)=\left\{\begin{array}{ll}
y-c_{1}\left(e_{L}, y\right)-\frac{c_{2}\left(e_{L}, y\right)}{R_{2}\left(1+\tau^{s}\left(e_{L}, y\right)\right)} & \text { if } y \in Y \\
y & \text { if } y \notin Y
\end{array} .\right.
$$


Next, we define the income and education contingent retirement savings subsidy as

$$
1+\tau^{s}(e, y)= \begin{cases}\frac{u^{\prime}\left(c_{1}(e, y)\right)}{\beta u^{\prime}\left(c_{2}(e, y)\right)} & \text { if } e \in\left\{e_{L}, e_{H}\right\} \\ 0 & \text { otherwise }\end{cases}
$$

Finally, we check that the policy instruments implement the optimum. First, notice that all agents choose $e \in\left\{e_{L}, e_{H}\right\}$, otherwise they will not have any retirement consumption. Next, for any $e \in\left\{e_{L}, e_{H}\right\}$ and $y$, agents at $t=1$ choose consumption to satisfy

$$
\frac{u^{\prime}\left(c_{1}\right)}{\beta u^{\prime}\left(c_{2}\right)}=1+\tau^{s}(e, y) \text { and } c_{1}+\frac{c_{2}}{R_{2}\left(1+\tau^{s}(e, y)\right)}=c_{1}(e, y)+\frac{c_{2}(e, y)}{R_{2}\left(1+\tau^{s}(e, y)\right)} \text {. }
$$

Clearly, agents optimally choose $c_{1}=c_{1}(e, y)$ and $c_{2}=c_{2}(e, y)$. Due to the income tax, all agents produce output $y \in Y$. Also, by the taxation principle, agents with productivity $\theta$ choose $y=y(e, \theta)$. For the final step, notice that given $L(e)$, agents with innate ability $\gamma$ optimally choose education level $e_{\gamma}$.

Proof of Proposition 4: By Lemma 3, we can define the optimal consumption derived from the direct mechanism as $\left(c_{0}(e), c_{1}(e, y), c_{2}(e, y)\right)$. Similarly, we focus on an implementation where agents do not purchase bonds due to the bond savings $\operatorname{tax} T^{k}(b)$, which is constructed as in the proof of Proposition 3.

For the policy instruments, we focus on an implementation where none of the agents save in the retirement savings account, so $s_{2}=0$. Agents with education $e_{L}$ rely on social security for retirement consumption while agents with education $e_{H}$ depend on social security benefits plus student loan repayment contributions in the retirement account. Let $y(\gamma, \theta)$ be the optimal output of type $(\gamma, \theta)$ agents in a direct revelation mechanism and define $Y=\{y \mid y=y(\gamma, \theta)$ with $\gamma \in\{L, H\}$ and $\theta \in \Theta\}$ to be the set of admissible income. First, we construct the matching rate $\alpha$ to be

$$
1+\alpha=\inf _{y \in Y, e \in\left\{e_{L}, e_{H}\right\}} \frac{u^{\prime}\left(c_{1}(e, y)\right)}{\beta u^{\prime}\left(c_{2}(e, y)\right)} .
$$

Next, we construct the social security benefit $a(y)=c_{2}\left(e_{L}, y\right)$. We set the income tax to be $T\left(y-s_{2}\right)=y-s_{2}-c_{1}\left(e_{L}, y\right)$, and the tax deduction from student loan repayment is

$$
g\left(R_{1}\left(e_{H}\right) r\left(e_{H}, y\right)\right)=R_{1}\left(e_{H}\right) r\left(e_{H}, y\right)-\left[c_{1}\left(e_{L}, y\right)-c_{1}\left(e_{H}, y\right)\right] \text { and } g(0)=0 \text {. }
$$

Finally, we construct the student loans and its income-contingent repayment schedule along 
with the tax on retirement savings account. Let the loan amount be defined as

$$
L(e)= \begin{cases}c_{0}(e)+e & \text { if } e \in\left\{e_{L}, e_{H}\right\} \\ 0 & \text { otherwise }\end{cases}
$$

and the income-contingent repayment schedule is $r\left(e_{L}, y\right)=0$ and

$$
r\left(e_{H}, y\right)=\frac{1}{\alpha R_{2} R_{1}\left(e_{H}\right)}\left[c_{2}\left(e_{H}, y\right)-c_{2}\left(e_{L}, y\right)+T^{r a}\right]
$$

We choose $T^{r a}$ such that $r\left(e_{H}, y\right)$ and $g\left(R_{1} r\right)$ are weakly positive. Let $T^{r a}(y)$ be a fictitious tax schedule defined as

$T^{r a}(y)=\max \left\{0, c_{2}\left(e_{L}, y\right)-c_{2}\left(e_{H}, y\right), c_{2}\left(e_{L}, y\right)-c_{2}\left(e_{H}, y\right)+\alpha R_{2}\left[c_{1}\left(e_{L}, y\right)-c_{1}\left(e_{H}, y\right)\right]\right\}$.

Observe that given $T^{r a}(y)$, both the repayment schedule and the tax deduction are weakly positive for any income. Lastly, by taking the supremum over all income, we obtain an income-independent lump-sum tax:

$$
T^{r a}=\sup _{y \in Y} T^{r a}(y)
$$

For our last step, we check that the policy instruments implement the optimum. First, notice that all agents would choose $e \in\left\{e_{L}, e_{H}\right\}$, otherwise $c_{0}=0$. Next, due to the low matching rate, all agents choose $s_{2}=0$. As a result, given the taxes and social security benefit, agents who invested $e_{L}$ consume $c_{1}=c_{1}\left(e_{L}, y\right)$ and $c_{2}=c_{2}\left(e_{L}, y\right)$. Next, for agents who invested $e_{H}$, given the taxes, $c_{1}=y-T(y)-g\left(R_{1}\left(e_{H}\right) r\left(e_{H}, y\right)\right)-R_{1}\left(e_{H}\right) r\left(e_{H}, y\right)$ and $c_{2}=a(y)+\alpha R_{2} R_{1}\left(e_{H}\right) r\left(e_{H}, y\right)-T^{r a}$, so they optimally choose $c_{1}=c_{1}\left(e_{H}, y\right)$ and $c_{2}=c_{2}\left(e_{H}, y\right)$. Also, by the taxation principle, agents with productivity $\theta$ choose $y=y(e, \theta)$. Finally, notice that given $L(e)$, agents with innate ability $\gamma$ optimally choose education level $e_{\gamma}$.

Proof of Proposition 5: With heterogeneous $\beta$, the government's problem remains the same except (9) is now

$$
U_{1}(\gamma, \theta)=u\left(c_{1}(\gamma, \theta)\right)-h\left(\frac{y(\gamma, \theta)}{\theta}\right)+\beta_{\gamma} \delta_{2} u\left(c_{2}(\gamma, \theta)\right)
$$


for all $\gamma$ and the ex-ante incentive constraint is

$$
\begin{aligned}
\delta_{0}\left(e_{H}\right) & u\left(c_{0}(H)\right)+\beta_{H} \delta_{1}\left(e_{H}\right) \int_{\underline{\theta}}^{\bar{\theta}}\left[U_{1}(H, \theta)+\left(1-\beta_{H}\right) \delta_{2} u\left(c_{2}(H, \theta)\right)\right] f\left(\theta \mid \kappa_{H}\right) d \theta \\
\geq & \delta_{0}\left(e_{L}\right) u\left(c_{0}(L)\right)+\beta_{H} \delta_{1}\left(e_{L}\right) \int_{\underline{\theta}}^{\bar{\theta}}\left[U_{1}(L, \theta)+\left(1-\beta_{L}\right) \delta_{2} u\left(c_{2}(L, \theta)\right)\right] f\left(\theta \mid \kappa_{L, H}\right) d \theta .
\end{aligned}
$$

The results follow from the procedures outlined in the proofs for Proposition 1 and Proposition 2.

Proof of Lemma 4: From Yu (2018a), we first choose the imaginary allocations such that it satisfies the preference arbitrage constraint: for any $\theta$,

$u\left(c_{1}^{I}\right)-h\left(\frac{y^{I}}{\theta}\right)+\hat{\beta} \delta_{2} u\left(c_{2}^{I}\right) \geq \max _{\hat{\theta}}\left\{u\left(c_{1}(H, \hat{\theta})\right)-h\left(\frac{y(H, \hat{\theta})}{\theta}\right)+\hat{\beta} \delta_{2} u\left(c_{2}(H, \hat{\theta})\right)\right\}$.

In essence, in $t=0$, agents believe their future-selves would choose the imaginary allocation over the real allocation. Notice that the real allocations may not be incentive compatible under the erroneous belief. Next, the imaginary allocations have to satisfy the executability constraints to makes sure that agents eventually choose the real allocation: for any $\theta$,

$$
U_{1}(H, \theta)=u\left(c_{1}(H, \theta)\right)-h\left(\frac{y(H, \theta)}{\theta}\right)+\beta \delta_{2} u\left(c_{2}(H, \theta)\right) \geq u\left(c_{1}^{I}\right)-h\left(\frac{y^{I}}{\theta}\right)+\beta \delta_{2} u\left(c_{2}^{I}\right) .
$$

Thus, the ex-ante incentive compatibility constraint is

$$
\delta_{0}\left(e_{H}\right) u\left(c_{0}(H)\right)+\beta \delta_{1}\left(e_{H}\right) \int_{\underline{\theta}}^{\bar{\theta}}\left[u\left(c_{1}^{I}\right)-h\left(\frac{y^{I}}{\theta}\right)+\delta_{2} u\left(c_{2}^{I}\right) .\right] f\left(\theta \mid \kappa_{H}\right) d \theta \geq U_{0}(L ; H) .
$$

Next, we show how the imaginary allocations can be designed such that the ex-ante incentive constraint is non-binding for all sophistication levels. Denote $I(\theta)=u\left(c_{1}^{I}\right)-h\left(\frac{y^{I}}{\theta}\right)$ and set $I(\theta)=U_{1}(H, \theta)-\beta \delta_{2} u\left(c_{2}^{I}\right)$ so the executability constraints are binding. Hence, the preference arbitrage constraints can be expressed as $u\left(c_{2}^{I}\right) \geq J(\theta, \hat{\beta})$, for all $\theta \in \Theta$ where $J(\theta, \hat{\beta})=\frac{\max _{\hat{\theta}}\left\{u\left(c_{1}(H, \hat{\theta})\right)-h\left(\frac{y(H, \hat{\theta})}{\theta}\right)+\hat{\beta} \delta_{2} u\left(c_{2}(H, \hat{\theta})\right)\right\}-U_{1}(H, \theta)}{(\hat{\beta}-\beta) \delta_{2}}$. Since the preference arbitrage constraints need to hold for all productivity realizations and sophistication, it is clear that $c_{2}^{I}$ is chosen to satisfy $u\left(c_{2}^{I}\right) \geq \max _{\theta, \hat{\beta}} J(\theta, \hat{\beta})$. Similarly, the ex-ante incentive constraint can be rewritten as $u\left(c_{2}^{I}\right) \geq K$, where $K=\frac{1}{(1-\beta) \delta_{2}}\left\{\frac{U_{0}(L ; H)-\delta_{0}\left(e_{H}\right) u\left(c_{0}(H)\right)}{\beta \delta_{1}\left(e_{H}\right)}-\int_{\underline{\theta}}^{\bar{\theta}} U_{1}(H, \theta) d F\left(\theta \mid \kappa_{H}\right)\right\}$. 
Since $u$ is unbounded above, for any real allocation, the imaginary retirement consumption $c_{2}^{I}$ can be chosen to satisfy $u\left(c_{2}^{I}\right) \geq \max \left\{\max _{\theta, \hat{\beta}} J(\theta, \hat{\beta}), K\right\}$. Also, since $u$ is unbounded below, it is possible to adjust $c_{1}^{I}$ for any given $y^{I}$ so that $I(\theta)=U_{1}(H, \theta)-\beta \delta_{2} u\left(c_{2}^{I}\right)$. As a result, it is always possible to find a single set of imaginary allocations for all levels of sophistication such that the ex-ante incentive constraints are non-binding for any allocation implemented on the equilibrium path.

Proof of Proposition 6: By Lemma 4, the optimization problem with non-sophisticated agents is the same as the original problem except the ex-ante incentive constraints are nonbinding, so $\mu=0$. As a result, the first order conditions are

$$
u^{\prime}\left(c_{0}(H)\right)=u^{\prime}\left(c_{0}(L)\right)=\phi
$$

and for all $\gamma$,

$$
\begin{gathered}
\pi_{\gamma} \delta_{1}\left(e_{\gamma}\right) f\left(\theta \mid \kappa_{\gamma}\right)-\xi_{\gamma}^{\prime}(\theta)=\lambda_{\gamma}(\theta), \\
(1-\beta) \pi_{\gamma} \delta_{1}\left(e_{\gamma}\right) f\left(\theta \mid \kappa_{\gamma}\right)+\beta \lambda_{\gamma}(\theta)=\frac{\phi \pi_{\gamma} \delta_{1}\left(e_{\gamma}\right) f\left(\theta \mid \kappa_{\gamma}\right)}{u^{\prime}\left(c_{2}(\gamma, \theta)\right)}, \\
\lambda_{\gamma}(\theta) u^{\prime}\left(c_{1}(\gamma, \theta)\right)=\phi \pi_{\gamma} \delta_{1}\left(e_{\gamma}\right) f\left(\theta \mid \kappa_{\gamma}\right), \\
\xi_{\gamma}(\underline{\theta})=\xi_{\gamma}(\bar{\theta})=0, \\
\lambda_{\gamma}(\theta) \frac{1}{\theta} h^{\prime}\left(\frac{y(\gamma, \theta)}{\theta}\right)+\xi_{\gamma}(\theta)\left[\frac{1}{\theta^{2}} h^{\prime}\left(\frac{y(\gamma, \theta)}{\theta}\right)+\frac{y(\gamma, \theta)}{\theta^{3}} h^{\prime \prime}\left(\frac{y(\gamma, \theta)}{\theta}\right)\right] \\
=\phi \pi_{\gamma} \delta_{1}\left(e_{\gamma}\right) f\left(\theta \mid \kappa_{\gamma}\right) .
\end{gathered}
$$

By rearranging the first order conditions, the results follow.

\section{B Approximating Current Policies}

To approximate current income taxes in the United States, we follow Heathcote et al. (2017) and set income tax $T(y)=y-\lambda y^{1-\tau}$. For education policies, college students have access to low-interest federal loans. In $t=0$, agents take out loans with gross interest $\underline{R}<R_{1}\left(e_{H}\right)$ for loans below $\bar{L}$. We model this as if agents who chose $e_{H}$ receive a lump-sum transfer of $T\left(e_{H}\right)=\underline{R} \bar{L}$ when they start working. Agents who choose $e_{L}$ do not receive this transfer. 
Upon retirement, agents receive social security benefits, which are income-dependent. The regulation below has been translated to fit the context of our model. To derive an agent's social security benefits, first calculate the agent's average indexed monthly earnings (AIME) which is defined as $A I M E=\frac{35}{45} \frac{y}{12}$ for any lifetime income $y$. In other words, the social security administration takes 35 of the highest annual incomes from the 45 years of the agent's work life and calculate the average monthly earnings. Next, based on 2015 social security regulations, the agent's monthly benefit $a(A I M E)$ is determined by the following replacement rates and bend points:

$$
a(A I M E)=\left\{\begin{array}{ll}
0.9 \times A I M E & \text { if } A I M E \leq 826 \\
743.4+0.32 \times(A I M E-826) & \text { if } 826<A I M E \leq 4,980 \\
2,072.68+0.15 \times(A I M E-4,980) & \text { if } 4,980<A I M E \leq 9,875 \\
2,806.93 & \text { if } A I M E>9,875
\end{array} .\right.
$$

Let $N$ denote the number of years agents spend in retirement, then in terms of lifetime income, the total benefit is

$$
A(y)= \begin{cases}\frac{0.9 y}{420} N & \text { if } y \leq 346,920 \\ {\left[743.4+0.32 \times\left(\frac{y}{420}-826\right)\right] N} & \text { if } 346,920<y \leq 2,091,600 \\ {\left[2,072.68+0.15 \times\left(\frac{y}{420}-4,980\right)\right] N} & \text { if } y>2,091,600\end{cases}
$$

Using 2015 regulations, agents are subject to a flat social security tax $T_{s}(y)$, which is defined as

$$
T_{s}(y)=\left\{\begin{array}{ll}
0.124 \times y & \text { if } y \leq 5,332,500 \\
661,230 & \text { if } y>5,332,500
\end{array} .\right.
$$

The tax is capped at an annual income of 118,500. Furthermore, the social security benefits are distributed from the social security tax.

We assume that agents accumulate retirement savings in a 401(k) account and a regular savings account which pays a gross interest of $R_{2}$. Let $s_{2}$ denote savings in a 401(k) account and $b_{2}$ in the regular savings account. Contributions to the 401(k) account are capped at an annual amount of 18,000 . We also assume an employer matching rate of $50 \%$. Contributions to defined contribution plans, such as $401(\mathrm{k})$, are pre-tax. This means that income tax payments are deferred upon withdrawal when retiring. However, social security tax is not deferred. Since contributions to 401(k) are matched, agents would first save in their 401(k) accounts until the cap binds, before saving in their regular accounts. 


\section{B.1 Deriving Allocations for Current Policies}

To determine the allocation of present-biased agents under the current policy, we adopt subgame perfect Nash equilibrium as our solution concept. By backward induction, agents with productivity $\theta$ who took out a loan of $b_{1}$ in $t=0$ and invested $e$ in education solve the following problem:

$$
\max \left\{u\left(c_{1}\right)-h(l)+\beta \delta_{2} u\left(c_{2}\right)\right\}
$$

subject to

$$
\begin{gathered}
c_{1}+b_{2}+s_{2}=\theta l-T\left(\theta l-s_{2}\right)-T_{s}(\theta l)-R_{1}(e) b_{1}+\mathbf{1}_{e=e_{H}} T\left(e_{H}\right), \\
c_{2}=1.5 R_{2} s_{2}+R_{2} b_{2}+A(\theta l)-T\left(1.5 R_{2} s_{2}\right), \\
s_{2} \leq \bar{c},
\end{gathered}
$$

where $\bar{c}$ is the upper-bound on contributions to the $401(\mathrm{k})$ account and $\mathbf{1}_{e=e_{H}}=1$ only if agents invested $e_{H}$. Let $\bar{\chi}_{t}(\theta)$ denote the multiplier on the period $t$ budget constraint for agents who invested $e_{H}$, and $\underline{\chi}_{t}(\theta)$ be the multiplier for low-educated agents.

\section{B.1.1 Using Only 401(k): $s_{2}<\bar{c}$}

We first look at agents who invested $e_{H}$. The first order conditions for consumption and savings $s_{2}$ are

$$
u^{\prime}\left(c_{1}\right)=\bar{\chi}_{1}(\theta), \beta \delta_{2} u^{\prime}\left(c_{2}\right)=\bar{\chi}_{2}(\theta) \text { and } \bar{\chi}_{1}(\theta)=\bar{\chi}_{2}(\theta) 1.5 R_{2}\left(\frac{\theta l-s_{2}}{1.5 R_{2} s_{2}}\right)^{\tau}
$$

This provides us with the following Euler equation:

$$
u^{\prime}\left(c_{1}\right)=1.5 \beta\left(\frac{\theta l-s_{2}}{1.5 R_{2} s_{2}}\right)^{\tau} u^{\prime}\left(c_{2}\right) \text {. }
$$

For labor supply, we have four different income regions to consider:

$$
h^{\prime}(l)=\left\{\begin{array}{ll}
\bar{\chi}_{2}(\theta)\left\{1.5 R_{2}\left(\frac{\theta l-s_{2}}{1.5 R_{2} s_{2}}\right)^{\tau} B\left(\theta, y, s_{2}\right)+\frac{0.9 N}{420} \theta\right\} & \text { if } y \leq 346,920 \\
\bar{\chi}_{2}(\theta)\left\{1.5 R_{2}\left(\frac{\theta l-s_{2}}{1.5 R_{2} s_{2}}\right)^{\tau} B\left(\theta, y, s_{2}\right)+\frac{0.32 N}{420} \theta\right\} & \text { if } 346,920<y \leq 2,091,600 \\
\bar{\chi}_{2}(\theta)\left\{1.5 R_{2}\left(\frac{\theta l-s_{2}}{1.5 R_{2} s_{2}}\right)^{\tau} B\left(\theta, y, s_{2}\right)+\frac{0.15 N}{420} \theta\right\} & \text { if } 2,091,600<y \leq 5,332,500 \\
\bar{\chi}_{2}(\theta)\left\{1.5 R_{2}\left(\frac{1}{1.5 R_{2} s_{2}}\right)^{\tau} \theta \lambda(1-\tau)+\frac{0.15 N}{420} \theta\right\} & \text { if } y>5,332,500
\end{array},\right.
$$


where $B\left(\theta, y, s_{2}\right)=\theta \lambda(1-\tau)\left(y-s_{2}\right)^{-\tau}-0.124 \theta$ As for agents who invested $e_{L}$, the first order conditions are the same except for replacing $\bar{\chi}_{t}(\theta)$ with $\underline{\chi}_{t}(\theta)$.

\section{B.1.2 Using Both 401(k) and Savings: $s_{2}=\bar{c}$ and $b_{2} \geq 0$}

We first analyze the case where agents invested $e_{H}$ in $t=0$. Suppose the agent has saved $s_{2}=\bar{c}$, then the agent can only continue to save with the standard savings account. We can rewrite the sequential budget constraint into its present value terms:

$$
c_{1}+\frac{c_{2}-\lambda\left(1.5 R_{2} \bar{c}\right)^{1-\tau}-A(\theta l)}{R_{2}}=\lambda(\theta l-\bar{c})^{1-\tau}-T_{s}(\theta l)-R_{1}\left(e_{H}\right) b_{1}+T\left(e_{H}\right) \text {. }
$$

Let $\bar{\chi}(\theta)$ denote the multiplier on the present-valued budget constraint. The first order conditions on consumption are

$$
u^{\prime}\left(c_{1}\right)=\bar{\chi}(\theta) \text { and } \beta u^{\prime}\left(c_{2}\right)=\bar{\chi}(\theta)
$$

The first order condition for labor is

$$
h^{\prime}(l)=\left\{\begin{array}{ll}
\bar{\chi}(\theta)\left[\theta \lambda(1-\tau)(\theta l-\bar{c})^{-\tau}-0.124 \theta+\frac{0.9 N}{420 R_{2}} \theta\right] & \text { if } \theta l \leq 346,920 \\
\bar{\chi}(\theta)\left[\theta \lambda(1-\tau)(\theta l-\bar{c})^{-\tau}-0.124 \theta+\frac{0.32 N}{420 R_{2}} \theta\right] & \text { if } 346,920<y \leq 2,091,600 \\
\bar{\chi}(\theta)\left[\theta \lambda(1-\tau)(\theta l-\bar{c})^{-\tau}-0.124 \theta+\frac{0.15 N}{420 R_{2}} \theta\right] & \text { if } 2,091,600<y \leq 5,332,500 \\
\bar{\chi}(\theta)\left[\theta \lambda(1-\tau)(\theta l-\bar{c})^{-\tau}+\frac{0.15 N}{420 R_{2}} \theta\right] & \text { if } y>5,332,500
\end{array},\right.
$$

We can derive a similar set of first order conditions for agents who obtained education level $e_{L}$.

\section{B.2 Calibration}

In this section we calibrate the model to resemble the "real world" as closely as possible. The goal is to back out the distribution of productivities across different education groups. To this extent, we first pick a number of parameters externally and summarize them in Table 4. Then, we calibrate the distributions of skills internally to match the evidence on lifetime earning provided by Cunha and Heckman (2007).

The values of risk aversion and Frisch elasticity of labor are standard and set to 2 and 0.5 , respectively. Next, we discuss the calibration of the current tax system. The parameters 
Table 4: Parameter values in the model

\begin{tabular}{|c|c|c|c|}
\hline Symbol & Meaning & Value & Source \\
\hline$\gamma$ & Risk aversion & 2 & \multirow{2}{*}{ Standard values } \\
\hline$\eta$ & Frisch elasticity & 0.5 & \\
\hline$\tau$ & Tax progressivity & 0.161 & \multirow{7}{*}{$\begin{array}{l}\text { Heathcote and } \\
\text { Tsujiyama (2017) }\end{array}$} \\
\hline$\lambda$ & Taxation level & 0.839 & \\
\hline $\bar{c}$ & 401(k) contribution limit & 1.80 & \\
\hline$C$ & Cost of college & 1.54 & \\
\hline$r_{m}$ & Commercial interest on student loans & 0.1 & \\
\hline$r_{g}$ & Government interest on student loans & 0.05 & \\
\hline $\bar{b}_{g}$ & Cap on government-subsidized student loans & 5.75 & \\
\hline$\beta$ & Short-term discount factor & 0.7 & \multirow{6}{*}{$\begin{array}{l}\text { Based on } \\
\text { Nakajima (2012) }\end{array}$} \\
\hline$\delta_{0}(L)$ & High school period 0 long-term discount factor & 0.00 & \\
\hline$\delta_{1}(L)$ & High school period 1 long-term discount factor & 1.00 & \\
\hline$\delta_{0}(H)$ & College period 0 long-term discount factor & 0.118 & \\
\hline$\delta_{1}(H)$ & College period 1 long-term discount factor & 0.942 & \\
\hline$\delta_{2}$ & Retirement discount factor & 0.270 & \\
\hline \multicolumn{3}{|c|}{ Time-consistent benchmark $(\beta=1)$} & \multirow{6}{*}{$\begin{array}{l}\text { Based on } \\
\text { Nakajima (2012) }\end{array}$} \\
\hline$\delta_{0}(L)$ & High school period 0 long-term discount factor & 0.00 & \\
\hline$\delta_{1}(L)$ & High school period 1 long-term discount factor & 1.00 & \\
\hline$\delta_{0}(H)$ & College period 0 long-term discount factor & 0.154 & \\
\hline$\delta_{1}(H)$ & College period 1 long-term discount factor & 0.885 & \\
\hline$\delta_{2}$ & Retirement discount factor & 0.154 & \\
\hline
\end{tabular}

Note: All monetary parameters are denominated in 10,000 of 2015 US dollars.

of the income tax function $\tau$ and $\lambda$ are borrowed from Heathcote and Tsujiyama (2017) and apply to income level normalized by average income in the economy. ${ }^{10}$ The upper bound for $401(\mathrm{k})$ contributions $\bar{c}$ is set to $\$ 18,000$ and reflects the present value of lifetime contribution limits based on the limit in 2015. The annual cost of college $C$ is assumed to be $\$ 15,400$, which is calculated for 2015 based on average tuition costs of private and public colleges ${ }^{11}$ as well as relative enrollment data for both types of college. ${ }^{12}$ As for the financing of student loans, we assume for simplicity that the annual interest rates an agent may obtained through private market and through a government-subsidized scheme are $10 \%$ and 5\%, respectively.

\footnotetext{
${ }^{10} \mathrm{We}$ calculate average income directly using the factual distributions of lifetime income from Cunha and Heckman (2007) and the shares of high school and college graduates of 0.64 and 0.36 , respectively. The average lifetime income amounts to $\$ 1,570,900$.

${ }^{11}$ Source: College Board, Annual Survey of Colleges and NCES, Digest of Education Statistics

${ }^{12}$ Source: NCES, Digest of Education Statistics.
} 
The amount of subsidized loan is capped at $\$ 57,500$, in line with the regulations for Stafford loans in the US. We further assume that an agent takes ten years to repay the student loans.

In calibrating the short- and long-term discount factors we primarily follow Nakajima (2012) who uses a general equilibrium model with present-biased agents and targets a capitaloutput ratio of 3 . We adopt his assumed value of the short-term discount factor of 0.7 which places in the midrange of estimates found by Laibson et al. (2017). The annual long-run discount factor is $\delta_{\text {annual }}=0.9852$ following Nakajima (2012) which we in turn use to calculate effective discount rates across the three periods in our model. These effective discount rate also reflect the relative lengths of the periods, which may differ across agents of different education groups. Because high school graduates start working right away, they never actually experience the education period 0 ; hence their parameter $\delta_{0}(L)$ is zero and $\delta_{1}(L)$ is one. On the other hand, college graduates spend 4 years in period 0 , and then another 45 years in period 1 . This yields $\delta_{0}(H)=\frac{1-\delta_{\text {annual }}^{4}}{1-\delta_{\text {annual }}^{45}}=0.118$ and $\delta_{1}(H)=$ $\frac{\delta_{\text {annual }}^{4}-\delta_{\text {annual }}^{49}}{1-\delta_{\text {annual }}^{45}}=0.942$. We assume that both education types spend 45 years working and 20 years in retirement. This yields a common retirement period discount factor of $\delta_{2}=$ $\frac{\delta_{\text {annual }}^{45}-\delta_{\text {annual }}^{65}}{1-\delta_{\text {annual }}^{45}}=0.270 .{ }^{13}$

For our analysis in the main body of the paper we also use the benchmark of timeconsistent agents, i.e. the world where $\beta=1$. For reference, we present here the analogous derivations of the effective long-run discount factors for that case. Once again following Nakajima (2012) we assume an annual discount rate $\delta_{\text {annual }}=0.9698$. Then, with the same reasoning we assume $\delta_{0}(L)=0$ and $\delta_{1}(L)=1$ for high school graduates, compared to $\delta_{0}(H)=0.154$ and $\delta_{1}(H)=0.885$ for college graduates. The discount factor for retirement amounts to $\delta_{2}=0.154$.

Having established the external parameters, we turn to the parameters governing the distribution of skills which are set through solving and simulating the model. For each of the four groups of agents: (i.) factual high school graduates, (ii.) high school graduates, had they gone to college, (iii.) factual college graduates, and (iv.) college graduates, had they not gone to college. We observe the empirical distributions of lifetime earnings reported by Cunha and Heckman (2007). Roughly speaking, these distributions are obtained by estimating a Roy-type model on combined NLSY and PSID data and generating counterfactuals for both education groups. As it is commonly known, panel surveys such as these tend to underrepresent the upper tail of the earnings distribution. For this reason, similarly as Findeisen and Sachs (2016), we add an upper tail from Pareto distribution with the shape parameter

\footnotetext{
${ }^{13}$ Because the college type first spends four years on education before they start to work, we assume that they also retire four years later, at age 67 , and live four years longer. This is consistent with a significant body of research which shows college graduates live longer than non-college graduates (Meara et al., 2008).
} 
of 1.5 (Saez (2001)). For each distribution, we select an income threshold at which we attach the Pareto tail such that the upper $10 \%$ of the mass is distributed according to it. We pick the scale parameter such that the (smoothed out) p.d.f. of the empirical distribution of earnings from Cunha and Heckman (2007) intersects at the threshold with the Pareto p.d.f.

Table 5: Adding a Pareto tail to lifetime income distributions

\begin{tabular}{lllll}
\hline & HS fact. & HS counter. & COL fact. & COL counter. \\
\hline Threshold & 200.1 & 249.8 & 277.4 & 207 \\
Scale parameter & 68.6 & 90.5 & 105.6 & 70 \\
\hline
\end{tabular}

Note: The thresholds refer to present value of lifetime earnings and are expressed in $\$ 10,000$ s of 2015 dollars. Thresholds are selected in each case such that $10 \%$ of total mass is distributed according to Pareto distribution with the shape parameter of 1.5.

To capture the earnings distribution with a fat upper tail in our model, we assume that agents' skills $\theta$ follow a mixture of two distributions, a normal distribution and a twopiece distribution (lognormal-Pareto) as described in Nigai (2017). The probability density function of our mixture is then given by

$$
\begin{aligned}
f(\theta) & =p \times\left[\frac{1}{2 \pi \sigma_{1}} \exp \left\{\frac{\left(\theta-\mu_{1}\right)^{2}}{2 \sigma_{1}^{2}}\right\}\right] \\
& +(1-p) \times \begin{cases}\frac{\rho}{\Phi(\alpha s(\alpha, \rho))} \frac{1}{\sqrt{2 \pi} s(\alpha, \rho) \theta} \exp \left\{-\frac{1}{2}\left(\alpha s(\alpha, \rho)-\frac{\log (\bar{\theta})-\log (\theta)}{s(\alpha, \rho)}\right)\right\}, & \text { if } \theta \in(0, \bar{\theta}) \\
(1-\rho) \frac{\alpha \bar{\theta}^{\alpha}}{\theta^{\alpha+1}}, & \text { if } \theta \in[\bar{\theta}, \infty)\end{cases}
\end{aligned}
$$

In equation (12), $\mu$ and $\sigma$ are the mean and standard deviation of the normal distribution, and $p$ is the probability of drawing it. The two-piece lognormal-Pareto distribution comes with a shape parameter $\alpha$, which we fix at 1.5, and two scale parameters, $\rho$ and $\bar{\theta}$. Intuitively, $\bar{\theta}$ is the threshold value at which the standard lognormal distribution turns into Pareto, while $\rho \in(0,1)$ represents the fraction of total mass that is distributed according to lognormal. We have hence 5 parameters to pin down for each of the four groups of agents, $(\mu, \sigma, \rho, \bar{\theta}, p)$, in order to replicate the empirical distributions of earning provided by Cunha and Heckman (2007) and augmented with the Pareto tail. To do so, we solve for the optimal policy functions in each of the four cases and simulate random draws for 100,000 agents. We use a global optimization algorithm to minimize the distance between the simulated CDF of lifetime earnings and the targeted one. Table 6 shows all components of our mixture density defined in (12) matter quantitatively and altogether result in a good fit for model-derived distributions of earnings in each group. Figures 6-7 depict the c.d.f. of lifetime earnings in the model and their empirical targets across the four groups of agents. 
Table 6: Parameters of productivity distributions

\begin{tabular}{llllll}
\hline \multirow{2}{*}{ Symbol } & \multirow{2}{*}{ Meaning } & HS fact. & HS counter. & COL fact. & COL counter. \\
& & 5.69 & 6.56 & 7.87 & 5.59 \\
$\mu$ & Mean of normal & 1.37 & 2.59 & 2.79 & 1.37 \\
$\sigma$ & St. dev. of normal & 1.37 & 9.18 & 0.53 \\
$\bar{\theta}$ & Threshold for Pareto & 5.91 & 7.42 & 0.51 & 0.53 \\
$\rho$ & Fraction of lognormal & 0.41 & 0.49 & 0.41 & 0.63 \\
$p$ & Probability of normal & 0.57 & 0.42 & & \\
\hline
\end{tabular}

Note: Productivities drawn from these distributions are in annual terms.
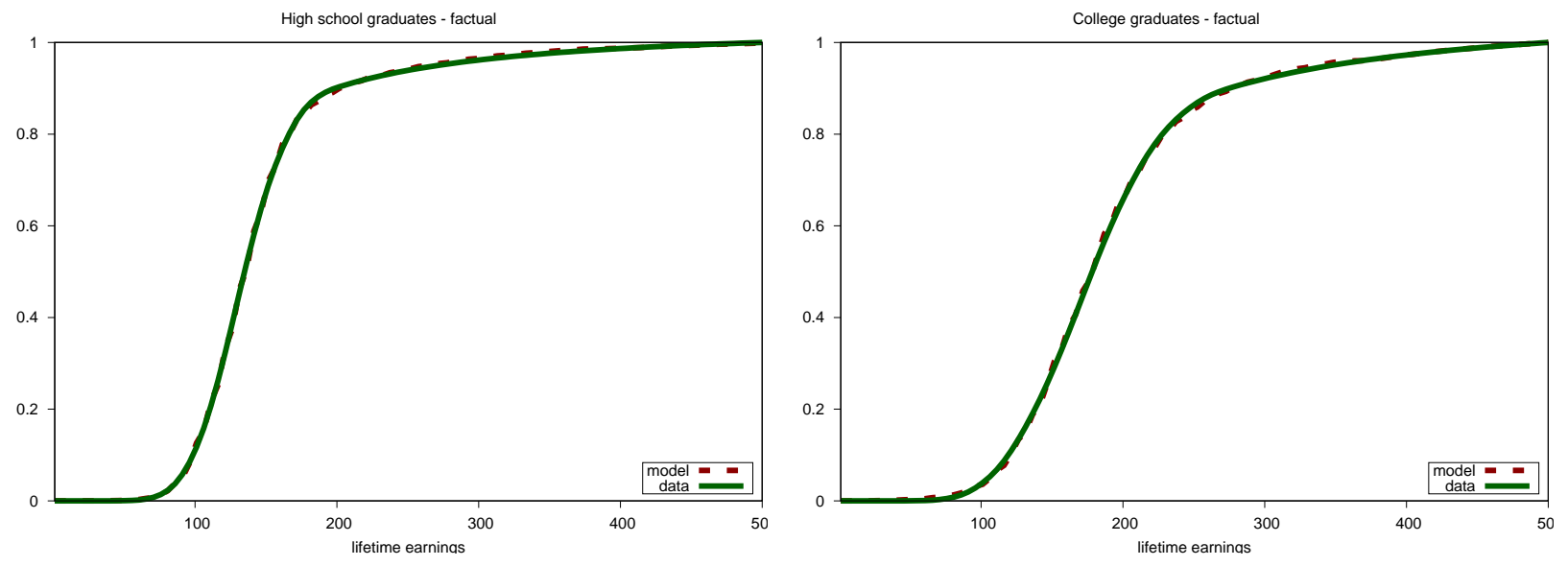

Figure 6: Distributions of lifetime income - factual
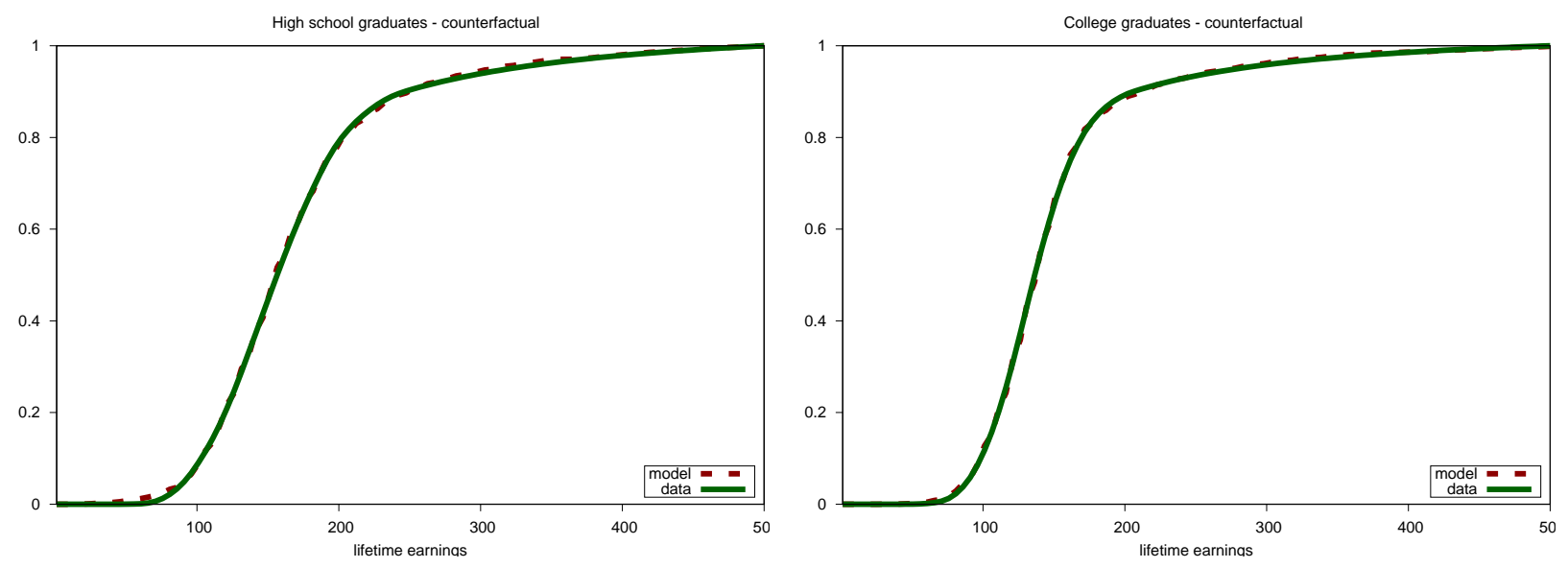

Figure 7: Distributions of lifetime income - counterfactual 


\section{Decomposition of the labor wedge}

In this section, we quantify the decomposition of the labor wedge introduced in Section 3.2. Figure 8 presents the numerical approximation of the labor wedge components A,C,D and $\mathrm{E}$ as function of income for the high innate ability type. ${ }^{14}$ The $\mathrm{A}$ components depends on the inverse hazard rate of the distribution of $\theta$ and declines at first, before increasing and converging to a constant due to the presence of a Pareto tail. By contrast, the intratemporal component $\mathrm{C}$ increases and then converges, resulting in the overall convergence of the labor wedge at the top of the distribution. The offsetting role that comes from the intertemporal component D is much smaller in size and decreases monotonically.

\section{Decomposition of the labor wedge}
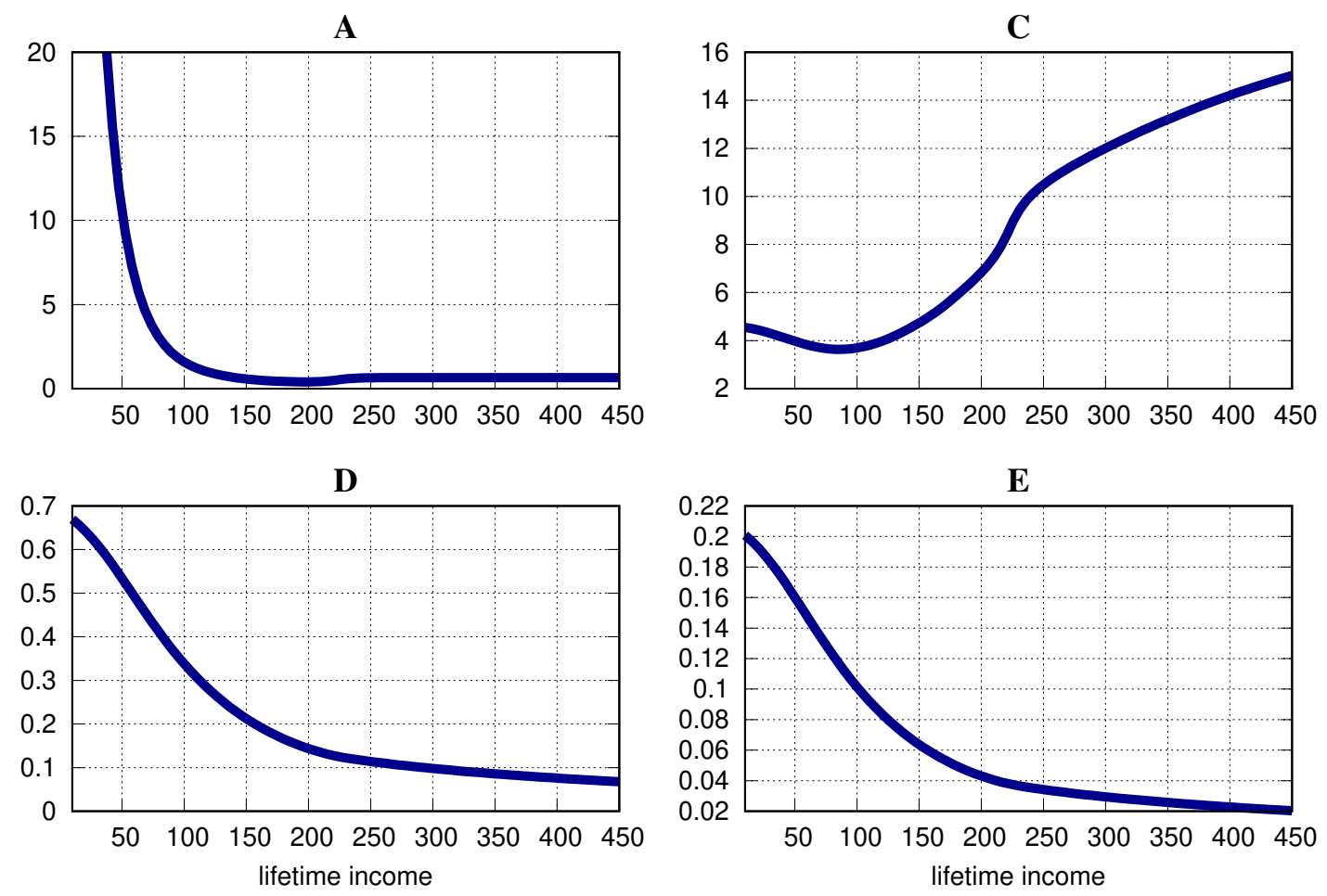

Figure 8: Labor wedge components for the high innate ability type

The novel aspect of our paper is the introduction of $\mathrm{E}$, the present bias component. As can be noticed, this components declines monotonically but its magnitude is also very small compared to components D, or especially C. Consequently, the labor wedge is generally not much affected by the present bias, and any difference shows up most prominently at the lowest levels of income, as evident in Figure 3.

\footnotetext{
${ }^{14}$ We ignore the B components because, given the functional forms we impose, it reduces to a constant. We also omit the decomposition for the low innate ability type because in our calibrated model the period-zero consumption of $L$-agents is not pinned down. As a result, the intertemporal component is not well-defined.
} 
To get a better understanding of this result, we can decompose the present bias element further into the disagreement component and the myopic component, as explained in Section 3.2. Figure 9 plots these two components on a single graph for the high innate ability type. Notice immediately that they offset each other for the most part and so the difference between them, the present bias component of the labor wedge, is quantitatively very small. This is similar for $L$-agents, which is plotted in Figure 10.

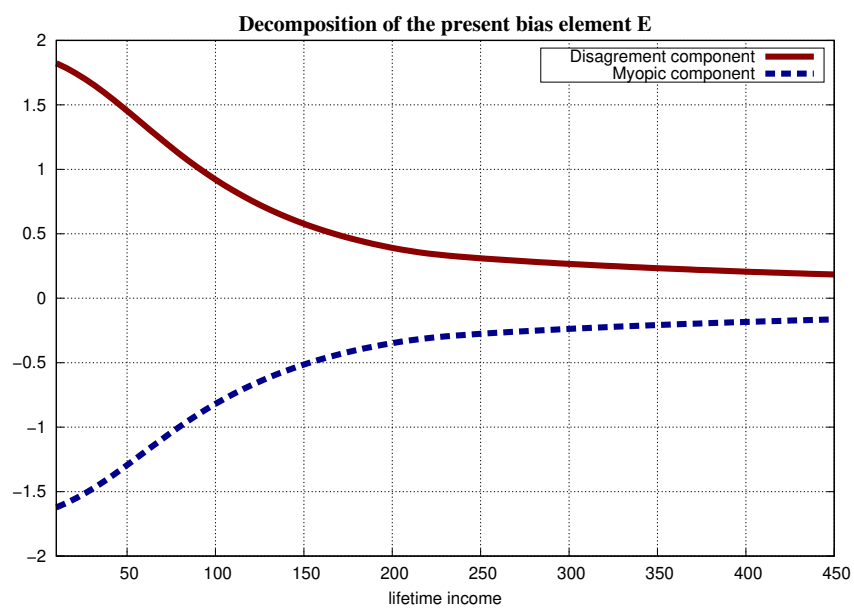

Figure 9: Decomposition of the present bias element of the labor wedge for $H$-agents

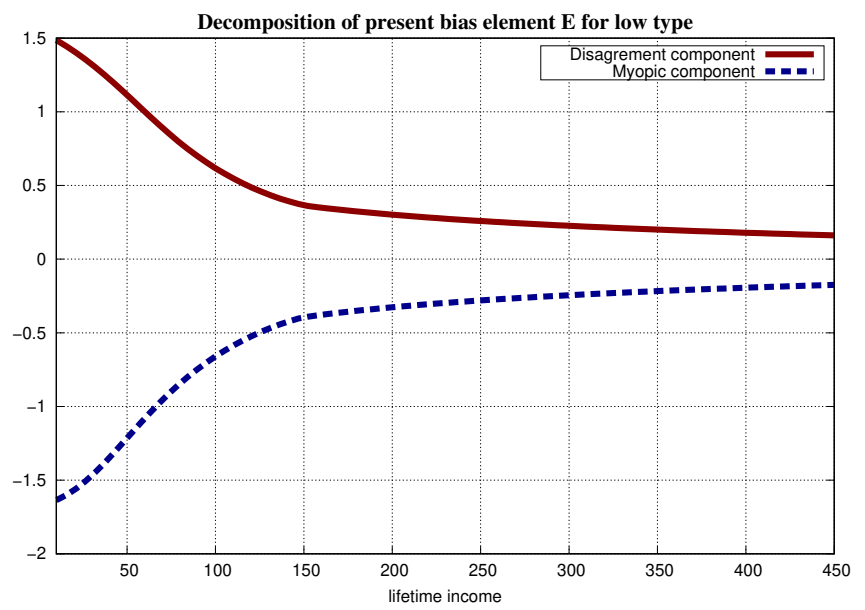

Figure 10: Decomposition of the present bias element of the labor wedge for $L$-agents 


\section{Time-Consistent benchmarks}

In this section, we present details of the implementation of the time-consistent optimal policies, which we use as benchmark for welfare calculations in Section 4.1. We consider two ways to implement the optimal allocation for time-consistent agents: mandatory retirement savings and laissez faire retirement savings. The two different implementations lead to different measures of welfare improvement.

First, we characterize the optimal allocations for time-consistent agents in a direct mechanism. Let $\left\{\tilde{c}_{0}(\gamma),\left[\tilde{c}_{t}(\gamma, \theta), \tilde{y}(\gamma, \theta)\right]_{t>0, \theta \in \Theta}\right\}$ be the optimal allocation for time-consistent agents. The optimal allocation for time-consistent agents satisfies the following:

$$
u^{\prime}\left(\tilde{c}_{1}(\gamma, \theta)\right)=u^{\prime}\left(\tilde{c}_{2}(\gamma, \theta)\right)
$$

This implies that $\tilde{c}_{1}(\gamma, \theta)=\tilde{c}_{2}(\gamma, \theta)=\tilde{c}(\gamma, \theta)$. For $t=0$, the government implements $\tilde{c}_{0}(\gamma)$ by providing agents a student loan of

$$
L\left(e_{H}\right)=\tilde{c}_{0}(H)+e_{H} \text { and } L\left(e_{L}\right)=\tilde{c}_{0}(L)+e_{L}
$$

Next, we proceed to consider two different methods to decentralize the optimal allocations in $t=1$ and $t=2$.

\section{D.1 Mandatory Savings}

Consider a mandatory minimum savings rule that forces agents to smooth consumption: $\tilde{c}_{1}(\gamma, \theta)=\tilde{c}_{2}(\gamma, \theta)$. For time-consistent agents, the policy implements the optimum. However, for present-biased agents, the minimum savings rule is not incentive compatible.

To see how the minimum savings rule changes the behavior of present-biased agents, we first analyze how agents would change their reports of $\theta$. Since for our quantitative exercise, $u(c)=\frac{c^{1-\sigma}}{1-\sigma}$ and $h\left(\frac{y}{\theta}\right)=\frac{1}{1+\frac{1}{\eta}}\left(\frac{y}{\theta}\right)^{1+\frac{1}{\eta}}$. Then, for a given report of innate ability $\hat{\gamma}$ and the time-consistent allocations, present-biased agents choose a report $\hat{\theta}$ to maximize the utility at $t=0$. In essence, a $\theta$-agent solves

$$
\max _{\hat{\theta}}\left\{u\left(\tilde{c}_{1}(\hat{\gamma}, \hat{\theta})\right)-h\left(\frac{\tilde{y}(\hat{\gamma}, \hat{\theta})}{\theta}\right)+\beta \delta_{2} u\left(\tilde{c}_{2}(\hat{\gamma}, \hat{\theta})\right)\right\} .
$$

From the argument above and the assumptions on the utility function, the problem can be 
rewritten as

$$
\max _{\hat{\theta}}\left\{u(\tilde{c}(\hat{\gamma}, \hat{\theta}))-\frac{1}{1+\frac{1}{\eta}}\left(\frac{\tilde{y}(\hat{\gamma}, \hat{\theta})}{\left(1+\beta \delta_{2}\right)^{\frac{1}{1+\frac{1}{\eta}}} \theta}\right)^{1+\frac{1}{\eta}}\right\} .
$$

We know that when $\beta=1$, the solution to the problem above is $\hat{\theta}=\theta$, because the mechanism satisfies incentive compatibility for time-consistent agents. Thus, we can transform the problem into the following alternative problem:

$$
\max _{\hat{\theta}}\left\{u(\tilde{c}(\hat{\gamma}, \hat{\theta}))-\frac{1}{1+\frac{1}{\eta}}\left(\frac{\tilde{y}(\hat{\gamma}, \hat{\theta})}{\alpha\left(1+\delta_{2}\right)^{\frac{1}{1+\frac{1}{\eta}}} \theta}\right)^{1+\frac{1}{\eta}}\right\},
$$

where $\alpha=\left(\frac{1+\beta \delta_{2}}{1+\delta_{2}}\right)^{\frac{1}{1+\frac{1}{\eta}}}$. In this case, the optimum is $\hat{\theta}=\alpha \theta$, because the problem is similar to a time-consistent agent with productivity $\alpha \theta$. As a result, the present-biased $\theta$-agents do not report truthfully and instead report

$$
\left(\frac{1+\beta \delta_{2}}{1+\delta_{2}}\right)^{\frac{1}{1+\frac{1}{\eta}}} \theta .
$$

This result is intuitive, because the reward for working is spread evenly between the two periods with mandatory savings. Since present-biased agents put less weight on retirement consumption, the mandatory savings policy provides less incentives for them to work. Their optimal strategy is to under-report their productivity and work less.

Finally, in $t=0$, agents know that they will report $\left(\frac{1+\beta \delta_{2}}{1+\delta_{2}}\right)^{\frac{1}{1+\frac{1}{\eta}}} \theta$ in $t=1$. As a result, given the optimal time-consistent allocation, $H$-agents solve the following:

$$
\begin{gathered}
\max \left\{u\left(\tilde{c}_{0}(H)\right)+\beta \frac{\delta_{1}\left(e_{H}\right)}{\delta_{0}\left(e_{H}\right)} \int_{\underline{\theta}}^{\bar{\theta}}\left[u\left(\tilde{c}_{1}(H, \hat{\theta})\right)-h\left(\frac{\tilde{y}(H, \hat{\theta})}{\theta}\right)+\delta_{2} u\left(\tilde{c}_{2}(H, \hat{\theta})\right)\right] d F\left(\theta \mid \kappa_{H}\right),\right. \\
\left.\frac{\delta_{0}\left(e_{L}\right)}{\delta_{0}\left(e_{H}\right)} u\left(\tilde{c}_{0}(L)\right)+\beta \frac{\delta_{1}\left(e_{L}\right)}{\delta_{0}\left(e_{H}\right)} \int_{\underline{\theta}}^{\bar{\theta}}\left[u\left(\tilde{c}_{1}(L, \hat{\theta})\right)-h\left(\frac{\tilde{y}(L, \hat{\theta})}{\theta}\right)+\delta_{2} u\left(\tilde{c}_{2}(L, \hat{\theta})\right)\right] d F\left(\theta \mid \kappa_{L, H}\right)\right\},
\end{gathered}
$$

where $\hat{\theta}=\left(\frac{1+\beta \delta_{2}}{1+\delta_{2}}\right)^{\frac{1}{1+\frac{1}{\eta}}} \theta$. 


\section{D.2 Laissez Faire Savings}

Another way to implement the optimum is for the government to allow agents to save freely for retirement. This is because with time-consistent agents, it is not necessary for the government to introduce any additional incentives for retirement savings. Hence, to implement the optimal allocation for time-consistent agents, the government only needs to introduce appropriate income taxes at $t=1$ and student loans in $t=0$. However, under laissez faire savings, present-biased agents do not smooth consumption and it is also not incentive compatible.

To find out how present-biased agents behave, we first derive the income tax $\tilde{T}(y)$ that implements the optimum for time-consistent agents. At $t=1$, time-consistent agents solves the following:

$$
\max _{c_{1}, c_{2}, y}\left\{u\left(c_{1}\right)-h\left(\frac{y}{\theta}\right)+\delta_{2} u\left(c_{2}\right)\right\}
$$

subject to

$$
c_{1}+s_{2}=y-\tilde{T}(y) \text { and } c_{2}=R_{2} s_{2}
$$

Let $\tilde{Y}$ be the set of optimal income for TC agents:

$$
\tilde{Y}=\{y \mid y=\tilde{y}(\gamma, \theta), \forall \gamma \in\{L, H\}, \theta \in \Theta\}
$$

By Lemma 3, we can rewrite the allocations in terms of income: $\tilde{c}_{t}(\tilde{y}(\gamma, \theta))=\tilde{c}(\gamma, \theta)$. As a result, we can define the following income tax, which implements the optimum for time-consistent agents:

$$
\tilde{T}(y)=\left\{\begin{array}{ll}
y & \text { if } y \notin \tilde{Y} \\
y-\tilde{c}(y)-\frac{1}{R_{2}} \tilde{c}(y) & \text { if } y \in \tilde{Y}
\end{array} .\right.
$$

For simplicity, we assume that if the government observes an off-path income level that it didn't expect, it usurps all of the output and leaves the agent without any consumption.

Next, we outline how present-biased agents behave under laissez faire savings. Given laissez faire savings and the income tax above, present-biased agents solve the following at $t=1$,

$$
\max _{c_{1}, c_{2}, y}\left\{u\left(c_{1}\right)-h\left(\frac{y}{\theta}\right)+\beta \delta_{2} u\left(c_{2}\right)\right\}
$$

subject to

$$
c_{1}+s_{2}=y-\tilde{T}(y) \text { and } c_{2}=R_{2} s_{2}
$$


We can rewrite the problem as

$$
\max _{c_{1}, c_{2}, y}\left\{u\left(c_{1}\right)-h\left(\frac{y}{\theta}\right)+\beta \delta_{2} u\left(c_{2}\right)\right\}
$$

subject to

$$
c_{1}+\frac{1}{R_{2}} c_{2}=\left(1+\frac{1}{R_{2}}\right) \tilde{c}(y) \text { and } y \in \tilde{Y} .
$$

It is clear that agents never choose $y \notin \tilde{Y}$, because all of the output would be confiscated. As a result, for any given $y \in \tilde{Y}$, present-biased agents choose consumption $\left(\hat{c}_{1}(y), \hat{c}_{2}(y)\right)$ to satisfy

$$
u^{\prime}\left(\hat{c}_{1}(y)\right)=\beta u^{\prime}\left(\hat{c}_{2}(y)\right)
$$

and

$$
\hat{c}_{1}(y)+\frac{1}{R_{2}} \hat{c}_{2}(y)=\tilde{c}(y)+\frac{1}{R_{2}} \tilde{c}(y) .
$$

It is obvious that agents do not choose the optimum for time-consistent agents. Hence, there will be intertemporal inefficiencies. In addition to the intertemporal inefficiencies, the agents might also choose suboptimal output. Agents choose $y$ by solving the following:

$$
\max _{y \in \tilde{Y}}\left\{u\left(\hat{c}_{1}(y)\right)-h\left(\frac{y}{\theta}\right)+\beta \delta_{2} u\left(\hat{c}_{2}(y)\right)\right\}
$$

where $\left(\hat{c}_{1}(y), \hat{c}_{2}(y)\right)$ are defined above.

After solving for the optimal allocations for $t=1,2$, we can solve for the agent's education choices in $t=0$. The process is the same as the one for mandatory savings.

\section{D.3 Welfare Comparisons}

To evaluate the welfare improvement of the paper's proposed policies, we measure the change of moving from mandatory savings or laissez faire savings to the policies introduced in Section 5.

However, this welfare evaluation is not straightforward. We need to guarantee the allocations chosen by present-biased agents under mandatory savings or laissez faire savings are feasible. This is because, from the analysis above, output of present-biased agents is further distorted under policies designed for TC agents. Therefore, the government budget constraint does not hold with present-biased agents under mandatory savings or laissez faire savings.

To facilitate the welfare comparison, we introduce an external government expenditure 
$G>0$ in the time-consistent setup, so that the resource constraint becomes

$$
\sum_{\gamma} \pi_{\gamma}\left\{-\frac{\tilde{c}_{0}(\gamma)}{R_{0}\left(e_{\gamma}\right)}-e_{\gamma}+\frac{1}{R_{1}\left(e_{\gamma}\right)} \int_{\Theta}\left[\tilde{y}(\gamma, \theta)-\tilde{c}_{1}(\gamma, \theta)-\frac{1}{R_{2}} \tilde{c}_{2}(\gamma, \theta)\right] f\left(\theta \mid \kappa_{\gamma}\right) d \theta\right\} \geq G .
$$

We interpret $G$ as an emergency fund the government uses to supplement the agents' consumption when total output is lower than expected. Hence, we require $G$ to be sufficiently large so that the allocations chosen by the present-biased agents, $\left\{\hat{c}_{0}(\gamma),\left[\hat{c}_{t}(\gamma, \theta), \hat{y}(\gamma, \theta)\right]_{t>0, \theta \in \Theta}\right\}$, are feasible:

$$
\sum_{\gamma} \pi_{\gamma}\left\{-\frac{\hat{c}_{0}(\gamma)}{R_{0}\left(e_{\gamma}\right)}-e_{\gamma}+\frac{1}{R_{1}\left(e_{\gamma}\right)} \int_{\Theta}\left[\hat{y}(\gamma, \theta)-\hat{c}_{1}(\gamma, \theta)-\frac{1}{R_{2}} \hat{c}_{2}(\gamma, \theta)\right] f\left(\theta \mid \kappa_{\gamma}\right) d \theta\right\} \geq 0
$$

\section{D.4 Quantitative Implementation}

In our quantitative exercise, we design a fixed-point algorithm to find the value of $G$ such that the resource constraint in (13) binds. The algorithm can be summarized as follows:

1. Start with an initial value for government spending $G_{0}$.

2. Solve for the optimal allocations with time-consistent agents.

3. Use the allocations, implemented either through mandatory savings or laissez-faire arrangement, to solve for the best response of present-biased agents. Calculate the resulting gap in the resource constraint which stems from present-biased agents underreporting their productivity type. Denote the gap $G_{1}$.

4. Check if $\left|G_{0}-G_{1}\right|<\varepsilon$, where $\varepsilon$ is a tolerance criterion. If yes, we have found a fixed point. If not, update $G_{0}$ and go back to step 1 .

Table 7 summarizes the fixed-point amount of government spending $G$ under both implementations which balances the resource constraint under present-biased agents.

Table 7: Fixed-point amount of government spending that balances the resource constraint

\begin{tabular}{cc}
\hline Mandatory savings & Laissez-faire \\
\hline 8.34 & 7.79 \\
\hline
\end{tabular}

